University of Nebraska - Lincoln

DigitalCommons@University of Nebraska - Lincoln

Publications, Agencies and Staff of the U.S.

Department of Commerce

U.S. Department of Commerce

2012

\title{
Arctic cloud macrophysical characteristics from CloudSat and CALIPSO
}

Yinghui Liu

University of Wisconsin, yinghuil@ssec.wisc.edu

Jeffrey R. Key

Center for Satellite Applications and Research

Steven A. Ackerman

University of Wisconsin

Gerald G. Mace

University of Utah

Qiuqing Zhang

University of Utah

Follow this and additional works at: https://digitalcommons.unl.edu/usdeptcommercepub

Part of the Environmental Sciences Commons

Liu, Yinghui; Key, Jeffrey R.; Ackerman, Steven A.; Mace, Gerald G.; and Zhang, Qiuqing, "Arctic cloud macrophysical characteristics from CloudSat and CALIPSO" (2012). Publications, Agencies and Staff of the U.S. Department of Commerce. 344.

https://digitalcommons.unl.edu/usdeptcommercepub/344

This Article is brought to you for free and open access by the U.S. Department of Commerce at DigitalCommons@University of Nebraska - Lincoln. It has been accepted for inclusion in Publications, Agencies and Staff of the U.S. Department of Commerce by an authorized administrator of DigitalCommons@University of Nebraska - Lincoln. 


\title{
Arctic cloud macrophysical characteristics from CloudSat and CALIPSO
}

\author{
Yinghui Liu ${ }^{\text {a,* }}$, Jeffrey R. Key ${ }^{\text {b }}$, Steven A. Ackerman ${ }^{\text {a,c }}$, Gerald G. Mace ${ }^{\mathrm{d}}$, Qiuqing Zhang ${ }^{\mathrm{d}}$ \\ a Cooperative Institute for Meteorological Satellite Studies, University of Wisconsin, Madison, WI, United States \\ b Center for Satellite Applications and Research, NOAA/NESDIS, Madison, WI, United States \\ c Department of Atmospheric and Oceanic Sciences, University of Wisconsin at Madison, Madison, WI, United States \\ ${ }^{d}$ Department of Atmospheric Sciences, University of Utah, Salt Lake City, UT, United States
}

\section{A R T I C L E I N F O}

\section{Article history:}

Received 22 October 2011

Received in revised form 6 May 2012

Accepted 8 May 2012

Available online $\mathrm{xxxx}$

\section{Keywords:}

Arctic

Cloud

Remote sensing

CloudSat

CALIPSO

\begin{abstract}
A B S T R A C T
The lidar and radar profiling capabilities of the CloudSat and Cloud-Aerosol Lidar and Infrared Pathfinder (CALIPSO) satellites provide opportunities to improve the characterization of cloud properties. An Arctic cloud climatology based on their observations may be fundamentally different from earlier Arctic cloud climatologies based on passive satellite observations, which have limited contrast between the cloud and underlying surface. Specifically, the Radar-Lidar Geometrical Profile product (RL-GEOPROF) provides cloud vertical profiles from the combination of active lidar and radar. Based on this data product for the period July 2006 to March 2011, this paper presents a new cloud macrophysical property characteristic analysis for the Arctic, including cloud occurrence fraction (COF), vertical distributions, and probability density functions (PDF) of cloud base and top heights. Seasonal mean COF shows maximum values in autumn, minimum values in winter, and moderate values in spring and summer; this seasonality is more prominent over the Arctic Ocean on the Pacific side. The mean ratios of multi-layer cloud to total cloud over the ocean and land are between $24 \%$ and $28 \%$. Low-level COFs are higher over ocean than over land. The ratio of low-level cloud to total cloud is also higher over ocean. Middle-level and high-level COFs are smaller over ocean than over land except in summer, and the ratios of middle-level and highlevel clouds to total cloud are also smaller over ocean. Over the central Arctic Ocean, PDFs of cloud top height and cloud bottom height show (1) two cloud top height PDF peaks, one for cloud top heights lower than $1200 \mathrm{~m}$ and another between 7 and $9 \mathrm{~km}$; and (2) high frequency for cloud base below $1000 \mathrm{~m}$ with the majority of cloud base heights lower than $2000 \mathrm{~m}$.
\end{abstract}

(c) 2012 Elsevier Inc. All rights reserved.

\section{Introduction}

An accurate determination of cloud amount and height is critical to studying the Arctic climate system and its changes. There are complex interactions between clouds and other processes in the Arctic climate system (Curry et al., 1996; Francis et al., 2009; Liu et al., 2009), and an accurate description of cloud macrophysical properties is important to understand and model these interactions. Arctic clouds are a key factor in determining the energy budget at the top of the atmosphere and at the surface by modulating the longwave and shortwave radiation fluxes (Intrieri et al., 2002; Tjernström et al., 2008), which affect the surface temperature and may regulate the growth or retreat of sea ice extent and thickness (Kay et al., 2008; Schweiger et al., 2008a). Liu et al. $(2008,2009)$ show that changes in cloud amount play a key role in the surface temperature changes in the Arctic. Wang and Key (2003) found that changes in Arctic cloud cover over the period 1982-1999, generally less cloud in winter and more in spring/summer, resulted in

\footnotetext{
* Corresponding author at: Cooperative Institute of Meteorological Satellite Studies, University of Wisconsin, 1225 West Dayton Street, Madison, WI 53706, United States. Tel.: + 1 6088901893; fax: + 16082625974 .

E-mail address: yinghuil@ssec.wisc.edu (Y. Liu).
}

a decreased warming/increased cooling effect of clouds on the surface. Wang and Key (2003) concluded that the surface temperature would have risen even higher than observed if cloud cover had not changed the way it did. Furthermore, cloud amount and cloud vertical structure change with the retreat of the sea ice cover (Kay and Gettelman, 2009; Schweiger et al., 2008b; Vavrus et al., 2011) and with changes in moisture convergence (Liu et al., 2007).

Cloud feedback is the primary source of uncertainty in projecting future climate change, especially in the Polar Regions (Solomon et al., 2007). Uncertainties result from limitations in scientific understanding of the cloud formation and dissipation processes (Beesley and Moritz, 1999; Vavrus and Waliser, 2008) and the lack of detailed observations of these processes. A better understanding of the Arctic climate system and forecasting of the Arctic climate require accurate observations of Arctic clouds.

Previous work made good progress in developing Arctic cloud detection algorithms and in deriving an Arctic cloud macrophysical property climatology from multiple observation platforms. Visual cloud reports from weather stations on land and ocean in the Arctic have been collected and processed to study the global cloud climatology (Hahn and Warren, 2003, 2007), and Arctic cloud inter-annual variability (Eastman and Warren, 2010). Dong et al. (2010) generated a 10-year climatology of 
Arctic cloud fraction and radiative forcing at Barrow, Alaska from radarlidar and ceilometer observations at the Atmospheric Radiation Measurement North Slope of Alaska site and the nearby NOAA Barrow Observatory from June 1998 to May 2008. Intrieri et al. (2002) reported the temporal distributions of cloudiness, and the vertical distribution of cloud boundary heights from combined radar and lidar observations onboard a ship from October 1997 to October 1998 during the Surface Heat Budget of the Arctic Ocean (SHEBA). Shupe et al. (2011) described cloud occurrence fraction, vertical distribution, boundary statistics, etc. based on combined observations of radar and lidar at six Arctic atmospheric observatories. The surface-based cloud observations have relatively low spatial resolutions and inhomogeneous observation locations, especially over the Arctic Ocean.

Observing clouds from satellites with passive sensors utilizes the differences in spectral signatures of clouds from surfaces in the visible, near-infrared, and thermal infrared channels, using the single- and multispectral threshold methods (Ackerman et al., 1998; Gao et al., 1998; Inoune, 1987; Minnis et al., 2001; Rossow and Schiffer, 1999; Schweiger et al., 1999; Spangenberg et al., 2001, 2002; Yamanouchi et al., 1987) and statistical classification methods (Ebert, 1989; Key, 1990; Key and Barry, 1989; Lubin and Morrow, 1998; Welch et al., 1988, 1990, 1992). Cloud climatologies have been derived from such satellite based passive observations (Fig. 1), e.g. the extended AVHRR (Advanced Very High Resolution Radiometer) Polar Pathfinder (APP-x; Wang and Key, 2005), the TIROS-N Operational Vertical Sounder (TOVS) Polar Pathfinder (TOVS Path-P; Schweiger et al., 1999), and the International Satellite Cloud Climatology Project (ISCCP; Rossow and Schiffer, 1999). Passive remote sensing has its challenges because of the poor thermal and visible contrast between clouds and the underlying snow and ice surface, small radiances from the cold polar atmosphere, and temperature inversions in the lower troposphere (Frey et al., 2008; Liu et al., 2004, 2010; Lubin and Morrow, 1998). These challenges, coupled with the scarcity of observations in the Arctic, inhibit the development of an accurate and consistent baseline of Arctic cloud properties. Arctic cloud amount simulations show significant inter-model differences in global and regional climate models, and with both surface and satellite observations (Birch et al., 2009; Inoue et al., 2006; Vavrus, 2004; Walsh et al., 2002, 2005).

Combining satellite based radar and lidar observations has the potential for accurately determining Arctic cloud amount with relatively high spatial resolution. The millimeter wavelength cloud profiling radar (CPR; Im et al., 2006) onboard CloudSat is able to penetrate almost all non-precipitating clouds, with limited sensitivity to optically thin

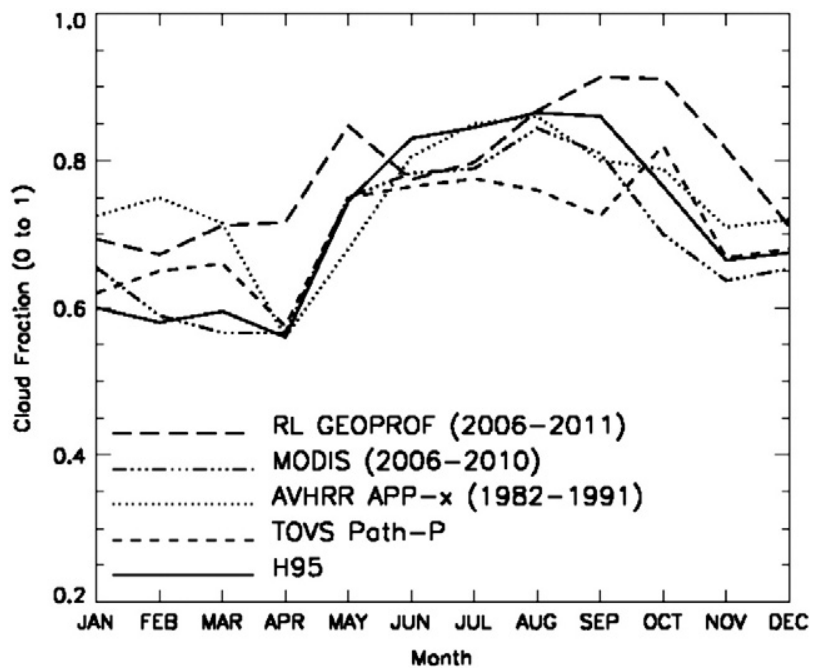

Fig. 1. Annual cycle of cloud fraction from surface-based observations (H95), TOVS Path-P (Wang and Key, 2005), AVHRR APP-x (Wang and Key, 2005), MODIS (2006-2010), and RL-GEOPROF (2006-2011). cirrus (Stephens et al., 2002, 2008), and has been used to study the vertical structure in the tropics (Yuan et al., 2011). The Cloud-Aerosol LIdar with Orthogonal Polarization (CALIOP) instrument onboard the CloudAerosol Lidar and Infrared Pathfinder Satellite Observation (CALIPSO) is sensitive to optically thin clouds (Winker et al., 2003) and has been used to determine probability density functions of cloud base and top heights and geometrical thickness of optically thin clouds (Devasthale et al., 2011). CloudSat and CALIPSO data complement each other, and a combination of both observations provides an opportunity of a description of cloud extent and distribution. These observations provide a reference for model simulations of Arctic clouds.

This study presents a description of the Arctic cloud occurrence fraction (COF), vertical distributions, and probability density functions (PDF) of cloud base and top heights based on combined observations of CloudSat and CALIPSO from July 2006 to March 2011. The data and the method to process the data are described in Section 2. Results and comparisons to some of the studies mentioned above are presented in Section 3. Conclusions and a discussion of the limitations and potential applications of this study are detailed in Section 4.

\section{Data and method}

The main data set in this study is the merged CloudSat geometrical profiling product (GEOPROF) (Marchand et al., 2008) and the CALIPSO Vertical Feature Mask (VFM) (Vaughan et al., 2009), which is referred to as the Radar-Lidar Geometrical Profile Product (RL-GEOPROF; Mace et al., 2009), from July 2006 to March 2011. CloudSat and CALIPSO are components of the A-Train satellite constellation (Stephens et al., 2002), with their nominal $705 \mathrm{~km}$ sun-synchronous orbits; during the period of this study, CALIPSO followed $15 \mathrm{~s}$ behind CloudSat and the instruments were navigated to observe the same locations on the earth's surface. A radar cloud mask stored in GEOPROF describes the significant radar echo mask at $240 \mathrm{~m}$ vertical and $2.4 \mathrm{~km}$ horizontal resolution. A vertical feature mask (VFM) is among several products created by analyzing the CALIOP sample volume (Vaughan et al., 2009). Using the radar cloud mask and the lidar VFM, RL-GEOPROF contains hydrometeor layer parameters of up to five layers, that include the cloud base and top heights of each hydrometeor layer above mean sea level in one radar footprint (approximately $2.5 \mathrm{~km}$ along by $1.5 \mathrm{~km}$ across track) with the longitude and latitude. Non-valid hydrometeor layers are filled with missing values.

In this study, a footprint is defined as cloud covered if there is at least one valid cloud base and top value in the five possible hydrometeor layers from RL-GEOPROF. In RL-GEOPROF, a cloudy range resolution volume is indicated when either the CPR cloud mask indicates the presence of a significant hydrometeor return (mask value of 20; Marchand, et al., 2008) or at least half of the CALIOP range resolution volumes within the CPR volume indicates the presence of a significant lidar return (Mace et al., 2009). Otherwise, the footprint is defined as being clear sky. Based on the top and base of the valid hydrometeor layer(s), if any part of the hydrometeor layer(s) is(are) between $0 \mathrm{~m}$ and $2000 \mathrm{~m}$ above the mean sea level, the footprint is defined as being covered by low-level cloud. Middle cloud is defined as between 2000 and $6000 \mathrm{~m}$; high cloud is between 6000 and $12,000 \mathrm{~m}$. The $12,000 \mathrm{~m}$ boundary is used to exclude polar stratosphere clouds. There is not a universal definition of low (middle, high) level cloud. For example, the definition of low (middle, high) level cloud by National Weather Service is a cloud base between 0 and $2 \mathrm{~km}(2$ and $4 \mathrm{~km}, 3$ and $8 \mathrm{~km})$ in the Polar Regions (http://www.srh. weather.gov/srh/jetstream/synoptic/clouds_max.htm); Met Office defines low (middle, high) level cloud as cloud bases between approximately 0 and $2 \mathrm{~km}$ ( 2 and $6 \mathrm{~km}, 6 \mathrm{~km}$ and above) (http://www.metoffice.gov. uk/learning/clouds/cloud-names-classifications). In this study, a cloud is defined as low (middle, high) level cloud if any part of the cloud is between 0 and $2 \mathrm{~km}$ ( 2 and $6 \mathrm{~km}, 6$ and $12 \mathrm{~km}$ ). For example, a footprint with a hydrometeor layer that has a cloud base lower than $2000 \mathrm{~m}$ and 
a cloud top higher than $6000 \mathrm{~m}$ is defined as being low-level, middlelevel, and high-level cloud covered.

If only one valid hydrometeor layer exists, the footprint is defined as being covered by a single-layer cloud. If more than one layer exists, the footprint is considered to be covered by a multi-layer cloud. Cloud top (base) height in a footprint is defined as the top (base) height of the highest (lowest) hydrometeor layer. The highest and lowest hydrometeor layers are the same when there is only one hydrometeor layer.

Monthly and seasonal mean COFs, cloud vertical distributions, and PDFs of cloud base and cloud top heights in the Arctic are derived as follows. Seasons are defined as spring (March, April, and May), summer (June, July, and August), autumn (September, October, and November), and winter (December, January, and February). The Arctic is defined here as the region north of $60^{\circ} \mathrm{N}$. The CloudSat and CALIPSO observations do not cover regions near the North Pole (approximately north of $82.5^{\circ} \mathrm{N}$ ). The Arctic is divided into $5^{\circ}$ longitude by $5^{\circ}$ latitude boxes. In each box, the cloud (low-level cloud, middle-level cloud, high-level cloud, single-layer cloud, and multi-layer cloud) occurrence fraction seasonal (monthly) mean is calculated as the ratio of cloud (low-level cloud, middle-level cloud, high-level cloud, single-layer cloud, multilayer cloud) covered footprint numbers to all footprint numbers falling in that box from the RL-GEOPROF in those same seasons (months) from July 2006 to March 2011. The ratio of low-level cloud (middle-level cloud, high-level cloud, single-layer cloud, and multi-layer cloud) frequency to the total cloud frequency is also calculated as the ratio of low-level (middle-level, high-level, single-layer, and multi-layer) cloud covered footprint numbers to all cloud covered footprint numbers. The sum of low, middle, and high-level cloud can exceed $100 \%$ because a footprint can be classified as being covered by more than one type of cloud based on cloud vertical extent.

The Arctic is also divided into 18 sub-areas, following the definition of Wang and Key (2005) (Fig. 2). One additional sub-area, the central Arctic Ocean, is defined as the region between 75 and $85^{\circ} \mathrm{N}$ latitude, and 0 and $240^{\circ}$ longitude. Area averaged mean COFs are calculated as defined above, except counting all the footprints in the defined area other than a 5 by $5^{\circ}$ box. PDFs of cloud top height (cloud base height) in a season/month in a box (sub-area) are derived using the cloud top height values in that box (sub-area) in those same seasons/months from July 2006 to March 2011, i.e. PDFs of cloud top height in winter over areas north of $75^{\circ} \mathrm{N}$ are derived using the cloud top height samples north of $75^{\circ} \mathrm{N}$ in all five winter seasons from 2006 to 2011. Figs. 4-11 (except Fig. 7) show the spatial distributions of parameters at 5 by $5^{\circ}$ resolution.

The merged CloudSat and CALIPSO product has its limitations. The CPR backscatter is strongly weighted to the largest particles in a resolution volume, so it is not possible to identify the cloud base in the presence of precipitation. Therefore, the layer base statistics reported herein will be biased low in precipitating clouds. The surface contributes a significant signal in the CloudSat measurements relative to the potential near surface hydrometeors because of the higher reflection of the surface (Marchand et al., 2008). In the latest version of CloudSat cloud mask (R04) (CloudSat 2B GEOPROF Quality Statement: May 2007), typically only rain and heavy drizzle can be detected around $480 \mathrm{~m}$ above the surface and moderate drizzle around $720 \mathrm{~m}$ above the surface. Surface contamination can be negligible from around $960 \mathrm{~m}$ above the surface. In the CloudSat cloud mask, a value of 5 is set to indicate a return power above the radar noise but indistinguishable from surface clutter (Marchand et al., 2008). A radar mask threshold of 20 is chosen (Mace et al., 2009), so that significant returns in the CloudSat measurements with likely surface clutter are not used during the merging of the CloudSat cloud mask and CALIPSO VFM. Though this approach avoids the surface contamination in the CloudSat measurements, the RL-GEOPROF products do not include clouds that can only be detected by CloudSat near the surface while there is nonnegligible surface contamination. The low-level COFs derived in this study thus are likely underestimated. In RL-GEOPROF, a separate layer is reported when at least an equivalent layer thickness for four resolution volumes, $960 \mathrm{~m}$, separates significant returns in a merged CPR-

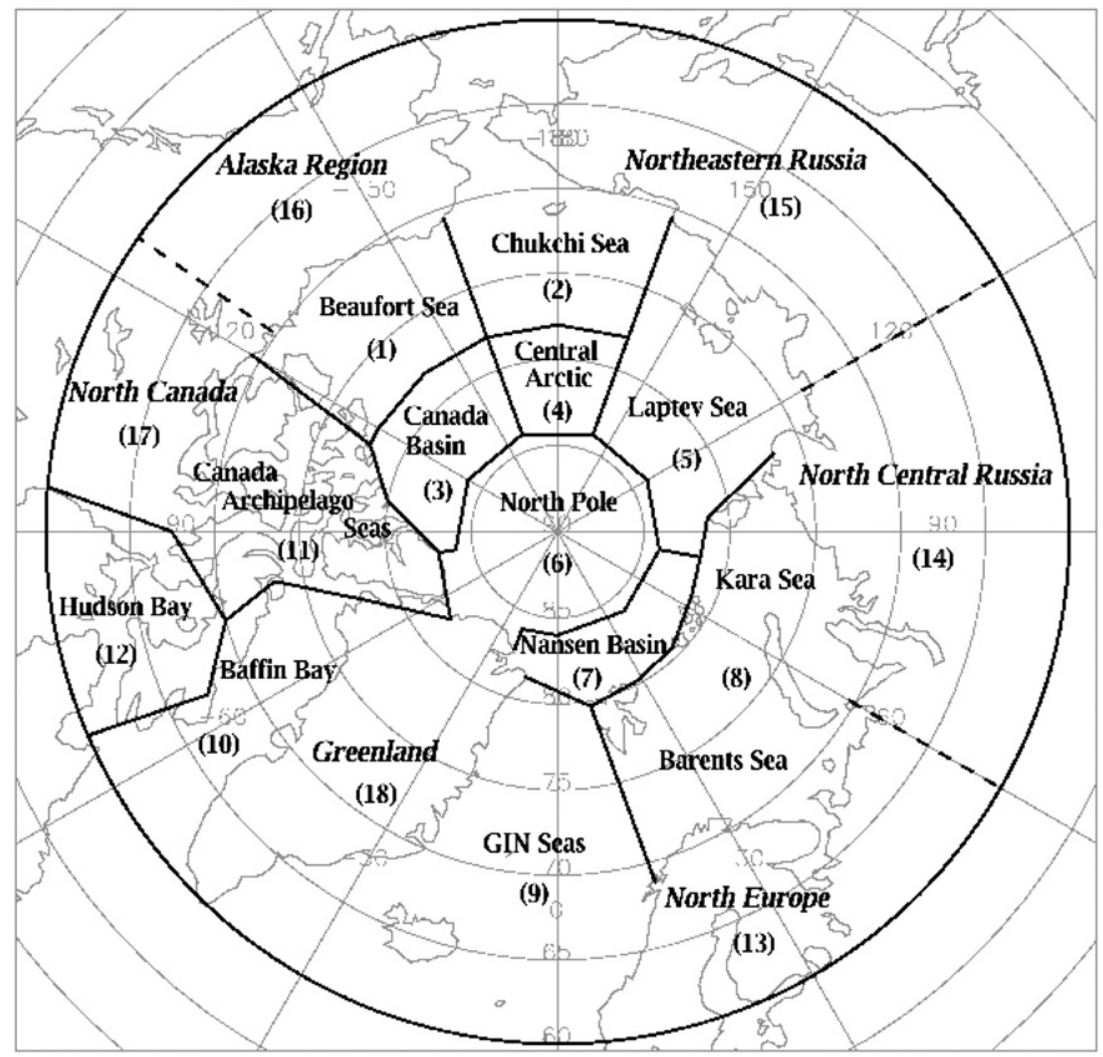

Fig. 2. Regional division of the Arctic north of $60^{\circ} \mathrm{N}$ (from Wang and Key, 2005). 
CALIOP profile. However, the separation of Arctic stratus is often less than $960 \mathrm{~m}$. As a result, the multi-layer COFs derived in this study are expected to be lower than the truth. These observational limitations very likely result in underestimations in the low-level cloud COF, multi-layer cloud COF, and uncertainties in cloud base height estimations.

Observed fractional cloud cover strongly depends on the threshold used to define the cloud presence for ground-based lidar (Eloranta et al., 2008). Cloud identification in RL-GEOPROF also depends on the threshold selected to define the cloud in GEOPROF and CALIPSO VFM. Uncertainties in cloud observations in the RL-GEOPROF might exist due to this threshold dependence. Another uncertainty in the RL-GEOPROF cloud information may come from the possible mis-identification of Arctic haze as cloud.

\section{Results}

\subsection{Seasonal mean cloud amount}

Meaningful monthly/seasonal mean COFs from the combined radar and lidar observations, (e.g. RL-GEOPROF) require large amounts of samples in each defined region. Otherwise, the derived means are not stable, and thus cannot represent the true monthly/seasonal means. Because CPR and CALIOP have only a near-nadir view, each granule of RLGEOPROF covers a much smaller area than granules from sensors with cross-track scanning (e.g. MODIS; Moderate Resolution Imaging Spectroradiometer with its $2330 \mathrm{~km}$ swath width). As a result, observations over a longer time period are required to accumulate enough footprints to derive representative monthly/seasonal means. The number of footprints falling in each 5 by $5^{\circ}$ box in each season from 2006 to 2011 is counted. The sample numbers inside the latitudinal belt between $72.5^{\circ} \mathrm{N}$ and $82.5^{\circ} \mathrm{N}$ are larger than those outside this belt, due to the orbital inclination of the satellites. In most boxes in winter, spring, summer, and autumn, there are over 80,000 samples within the latitudinal belt between $72.5^{\circ} \mathrm{N}$ and $82.5^{\circ} \mathrm{N}$. Seasonal mean COFs changing with sample numbers are derived in every 5 by $5^{\circ}$ box. At a fixed sample number, each one of those samples is randomly selected from all available samples, and a seasonal COF is then calculated from those random selected samples. This process is repeated 10 times for each sample number. An example for a box centered at longitude $152.5^{\circ}$ and latitude $72.5^{\circ}$ is shown in Fig. 3. The seasonal mean COFs are unstable with sample numbers less than 10,000, and become stable when the sample
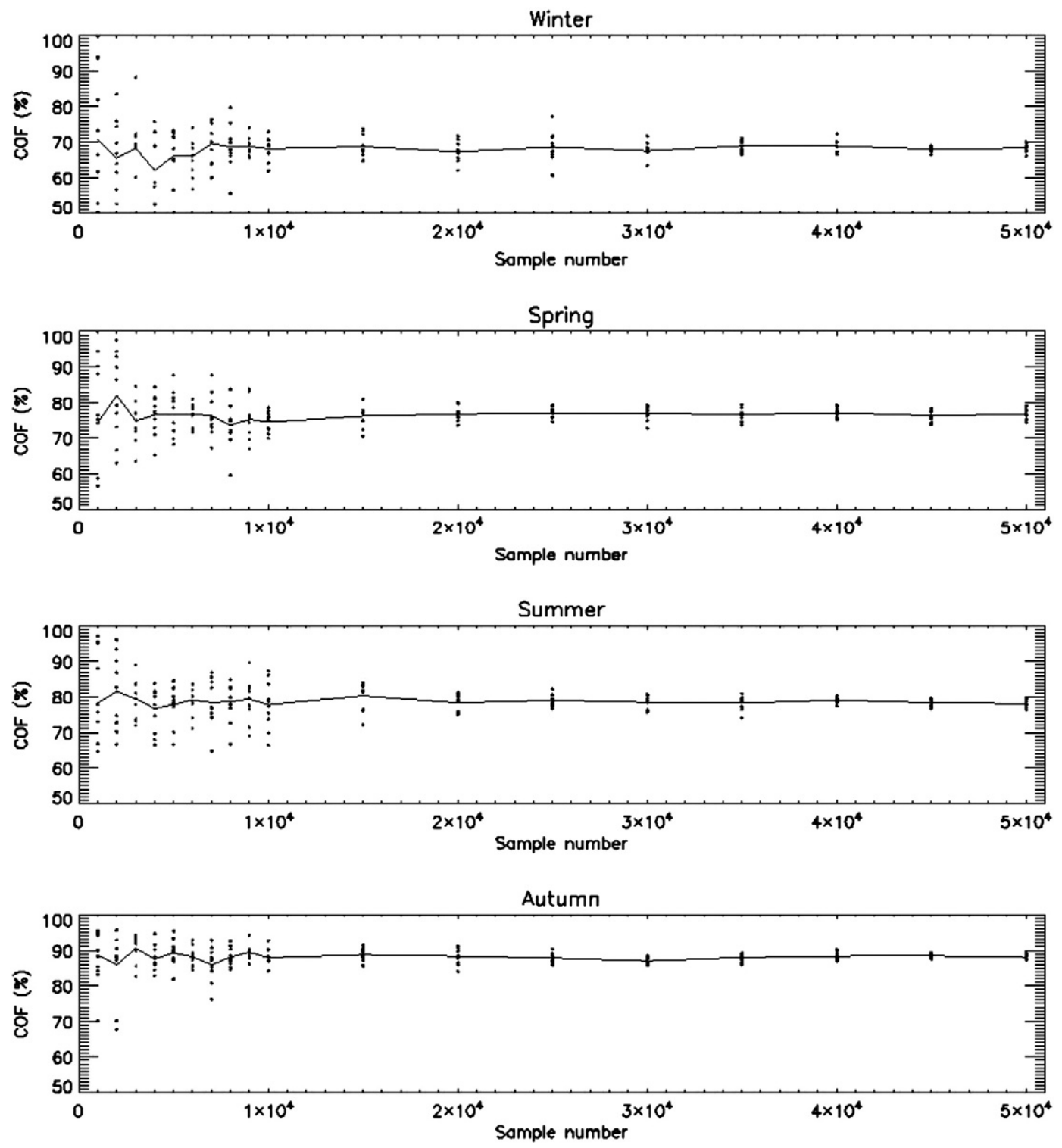

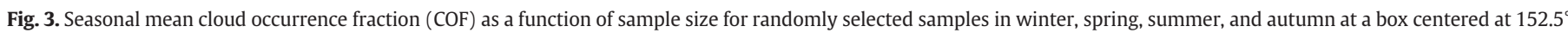

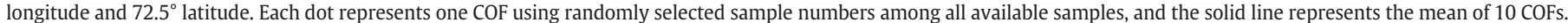


numbers exceed 35,000. It should be noted that the overlaps of the randomly selected samples increase with increasing sample number. Though the scatter of the cloud frequencies decreases with increasing sample number, it does not necessarily prove that 70,000 or 80,000 radar/lidar nadir view samples are enough to depict the true cloud frequency characteristics.

Seasonal mean Arctic COF shows different spatial distributions during the seasons (Fig. 4). The winter mean COF is relatively higher averaged over the Arctic Ocean (which includes the entire ocean area except Baffin Bay) than the average over the Arctic land (the entire land area except Greenland). The higher values over the Arctic Ocean are due to the very high COF values over the Arctic Ocean on the Atlantic side. Over the Arctic Ocean on the Pacific side, the COF is low. Over the Arctic land on the North America side, the minimum COF appears over the Canada Archipelago and northern Canada under possible influence of the Arctic Ocean, and COF increases over Alaska. On the Euro-Asia side, the minimum COF is over northeastern Russia, increasing westward to northern Europe. In spring and summer, mean COFs over the Arctic Ocean increase. The contrast between the Pacific side and Atlantic side of the Arctic Ocean is weaker in spring and summer, and is less heterogeneous over land. In autumn, COFs are at the highest over both ocean and land. COFs over the Arctic Ocean are higher than those over the Arctic land, with high values over the Arctic Ocean on both the Atlantic side and Pacific side.

Seasonality of the Arctic COF is most obvious over the Arctic Ocean on the Pacific side, with mean seasonal COFs being low in winter, high in autumn, and moderate in spring and summer (for example, 64\%, 71\%, $75 \%$, and $89 \%$ over the Chukchi Sea in winter, spring, summer, and autumn respectively, hereafter the four values are noted for the four seasons). This seasonality does not occur over the Greenland-IcelandNorwegian (GIN) Seas (86\%, 86\%, 81\%, and 86\%), and the Barents Sea (83\%, $82 \%, 83 \%$, and $91 \%)$. Differences of means t-tests show significant seasonal mean COF differences between every two seasons over the
Arctic Ocean on the Pacific side, and significant mean COF differences between autumn and other seasons on the Atlantic side. Mean COF over the Arctic land shows similar COFs in winter, spring, and summer $(70 \%, 71 \%$, and $73 \%$ ), with a higher COF value in autumn (81\%) and with similar seasonality over the Euro-Asia side. Over the North America side, it appears the seasonality is somewhat affected by the COF seasonality over the Arctic Ocean, with low COF in winter, increasing gradually from winter to autumn, and highest in autumn. Over Alaska, the seasonality is represented as low COF values in winter and spring (71\% and $72 \%$ ), and increased values in summer and autumn (77\% and 78\%).

With regard to the COF annual cycle, the RL-GEOPROF COF averaged over the central Arctic Ocean has minimum values in February (67\%), increases gradually, except for a significant increase in May, and reaches maximum values in August, September, and October (87\%, 91\%, and 91\%), then decreases (Fig. 1). Intrieri et al. (2002) report a similar annual cycle of cloud occurrence mainly over the Beaufort Sea based on surface radar and lidar observations, with a late summer and early fall maximum (97\% in September) and winter minimum (63\% in February) (Fig. 5 in their paper). Shupe et al. (2011) also describe a clear annual cycle in COF, minimum in winter and maximum in late summer and autumn. The Arctic COF annual cycle over a similar region (north of $80^{\circ} \mathrm{N}$ ) from surface observations (H95) (Hahn et al., 1995) and other satellite datasets (e.g. MODIS, APP-X, and TOVS Path-P) shows low COF from November to April and high COF from June to September (Wang and Key, 2005). Compared to those distributions of H95 and from satellites, RL-GEOPROF COF values are higher most of the year except June, July, and August. The higher cloud amount from RL-GEOPROF likely results from the higher sensitivity of radar/lidar observations to thin cloud layers, which may account for about $10 \%$ of the difference considering the total cloud fraction and percentage of thin clouds estimated by Minnis et al. (2008a), and better detection capability at night when the cloud signal in visible channels is not available.
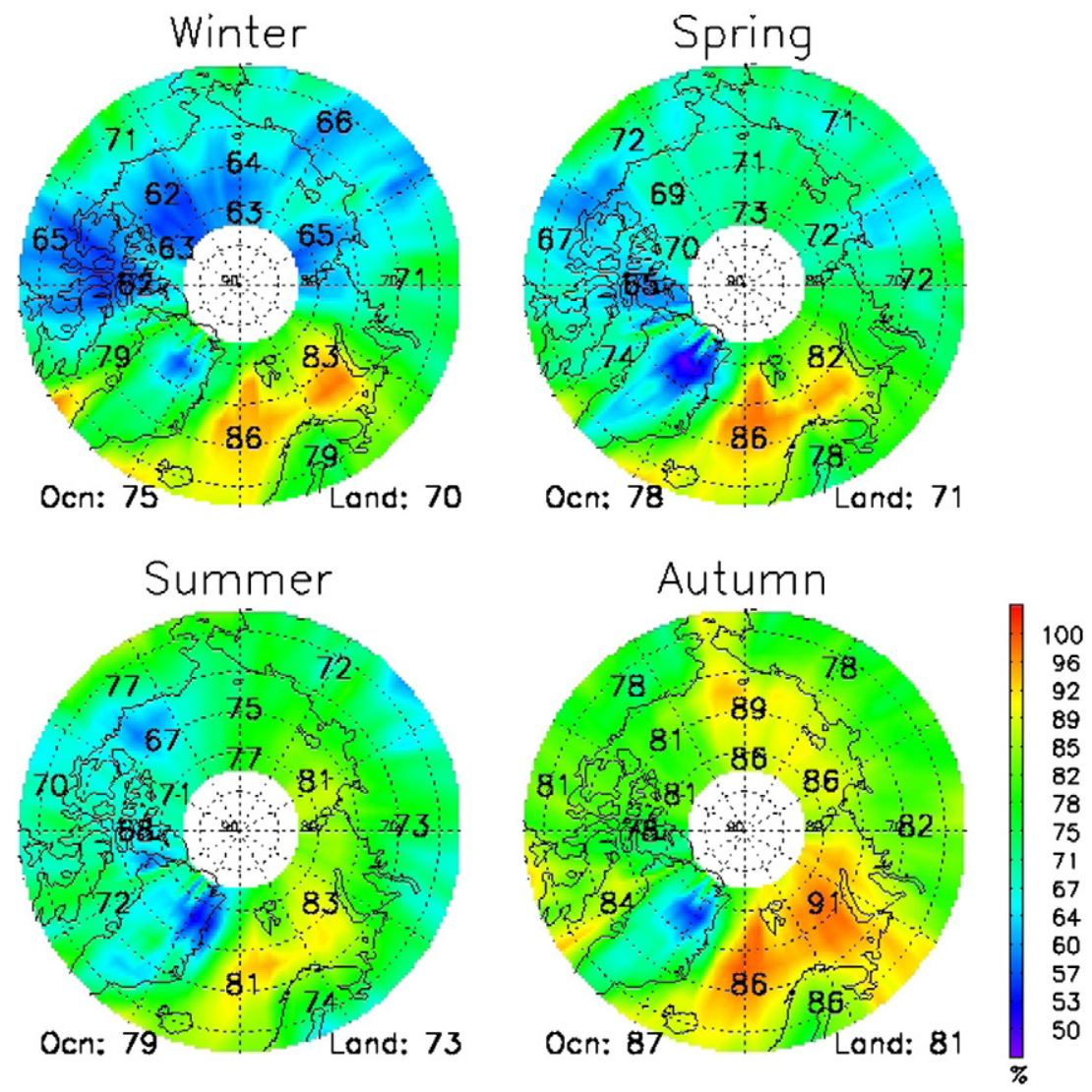

Fig. 4. Total cloud frequencies in winter, spring, summer, and autumn from RL-GEOPROF from 2006 to 2011 . Numbers show the averages over different sub-regions in Fig. 2. 
A thick Arctic haze layer has high backscatter and can be mistaken as cloud. Such a haze layer appears mainly in late winter and early spring due to the intense meridional transport from the midlatitudes and a minimum removal process (Quinn et al., 2007). The possible misidentification of Arctic haze as cloud might contribute the higher cloud amount over the Arctic Ocean in late winter and early spring. In RL-GEOPROF, a cloudy range resolution volume is indicated when either the CPR cloud mask indicates a significant hydrometeor return or at least half of the CALIOP range resolution volumes within the CPR volume indicates the presence of a significant lidar return, and this threshold requirement (0.5) might underestimate the clouds with small spatial extent.

\subsection{Single-layer and multi-layer cloud seasonal means and area averages}

Knowledge of vertical profiles of cloudiness is important for radiative flux calculations in the atmosphere, at both the surface and the top of the atmosphere (Kato et al., 2010), and should be a fundamental piece of information in standard satellite-derived cloud data (Heidinger and Pavolonis, 2005). Satellite passive sensors can detect semitransparent cirrus overlapping a lower level cloud, but cannot discern multiple layers when the top cloud layer is optically thick. Lidar is capable of detecting thin cirrus, but is attenuated by optically thick clouds; CloudSat is insensitive to thin cirrus with small particle size, but can penetrate almost all non-precipitating clouds. Combining observations, e.g. the RL-GEOPROF, can provide better information on cloud vertical distributions, including cloud overlap than in situ, and satellite passive sensors, and better spatial coverage than surface based radar/lidar observations.

RL-GEOPROF single pixel cloud products provide cloud top and base heights for up to five cloud layers. Seasonal multi-layer cloud (from two-layer to five-layer clouds) and single-layer cloud distributions are derived. The ratio of multi-layer cloud frequency to the total cloud frequency is shown in Fig. 5, Mean ratios over the Arctic Ocean (26\%, 26\%, 26\%, and 28\%), and over the Arctic land (24\%, 24\%, 27\%, and $27 \%$ ) are between 24 and $28 \%$. The ratios are relatively higher on the Atlantic side than on the Pacific side of the Arctic Ocean, especially in winter. In terms of seasonality, an apparent annual cycle appears over the Arctic Ocean on the Pacific side, with low values in winter and high values in autumn. The ratios are nearly constant over the Arctic Ocean on the Atlantic side. Combining total COF and the ratio of multi-layer cloud frequency to total cloud frequency, the seasonal mean multi-layer COFs in the Arctic (not shown) show high values over the GIN Seas $(26 \%, 26 \%, 23 \%$, and $26 \%)$, Barents Sea $(26 \%, 23 \%$, $23 \%$, and $28 \%$ ), and northern Europe $(26 \%, 22 \%, 20 \%$, and $28 \%)$, and very low values over the Arctic Ocean on the Pacific side, the Canada Archipelago, and northern Canada. Overall, the multi-layer cloud frequencies are higher over ocean $(20 \%, 21 \%, 21 \%$, and $25 \%)$ than over land $(17 \%, 17 \%, 19 \%$, and $22 \%)$ in the Arctic. The multi-layer cloud frequency shows minimum values in winter, increases in spring and summer, and shows maximum values in autumn over most of the Arctic except for the GIN seas, Barents Sea, northern Europe, and Alaska.

The seasonal distribution and seasonality of ratios of single-layer cloud frequency to total cloud frequency are the opposite of the ratios of multi-layer cloud frequency to total cloud frequency (not shown). Combining this ratio and total cloud frequency, the seasonal mean single-layer COFs are $55 \%, 57 \%, 58 \%$, and $62 \%$ over the Arctic Ocean, and $52 \%, 53 \%, 53 \%$, and $58 \%$ over the Arctic land for the four seasons (Fig. 6). Over the Arctic Ocean, the values over the Atlantic side are higher than those over the Pacific side in winter and spring. Over the Arctic land, the values are relatively evenly distributed. The seasonality presents higher single-layer cloud frequency in autumn than in other seasons over both land and ocean.

Over the central Arctic Ocean, multi-layer COFs are approximately $20 \%$ throughout the year, with slightly higher values in September and October (Fig. 7). Single-layer COFs have relatively larger
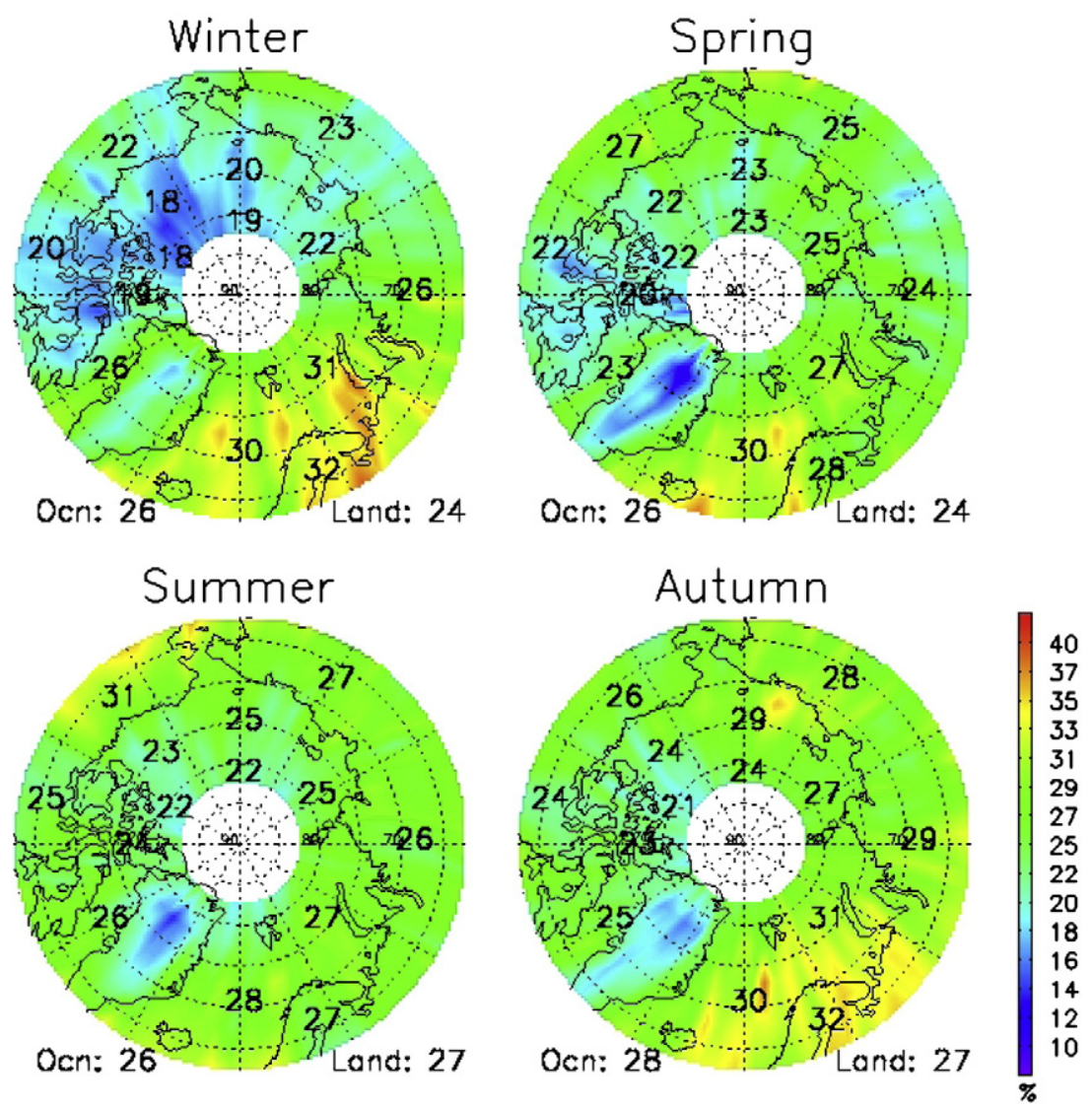

Fig. 5. Ratio of multi-layer cloud to total cloud frequencies in winter, spring, summer, and autumn from RL-GEOPROF from 2006 to 2011. 

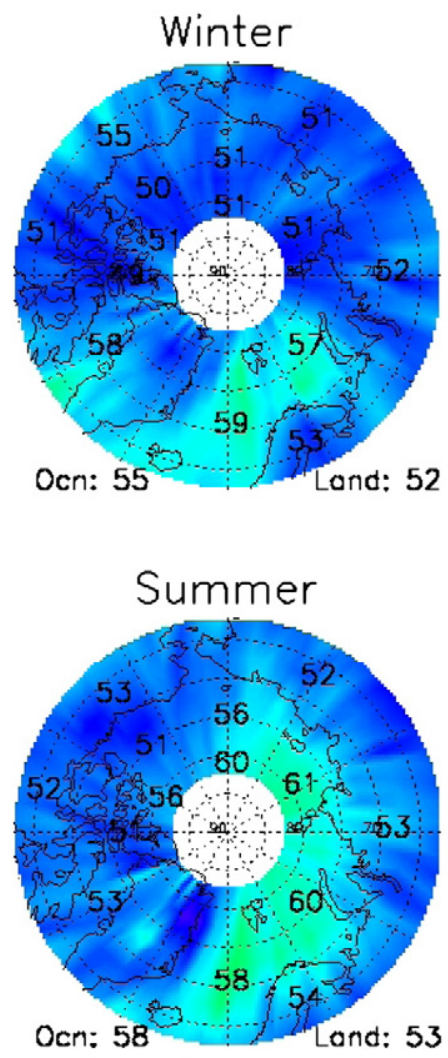

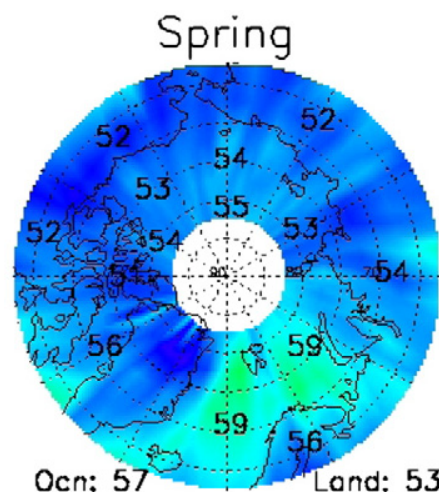

Autumn

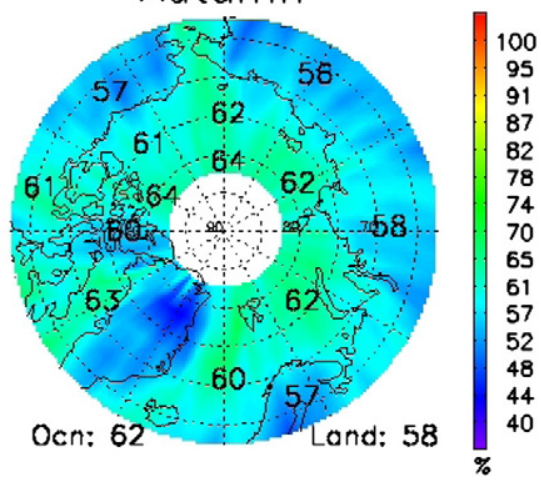

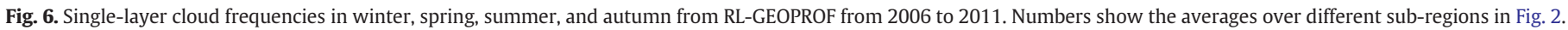

amplitude and fluctuations in their annual cycle, with low values in winter (53\%) and higher values in autumn (63\%). Percentages of single-layer cloud and multi-layer cloud frequencies to the total cloud frequencies are relatively constant throughout the year, 25\% and $75 \%$ respectively.

Multi-layer COFs are $17 \%, 17 \%, 19 \%$, and $22 \%$ over Arctic land, and $20 \%, 21 \%, 21 \%$, and $25 \%$ over Arctic Ocean in winter, spring, summer, and autumn. The mean ratios of multi-layer cloud to total cloud are between $24 \%$ and $28 \%$ over both ocean and land. Heidinger and Pavolonis (2005) show zonal mean percentages of cirrus overlapping lower clouds in the Arctic from a minimum of $13 \%$ to a maximum of $25 \%$ in July based on observations from satellite passive sensors.

Multiple layering is frequently observed in the Arctic summertime boundary layer and separations between layers are around several hundred meters (Curry et al., 1988; Herman and Goody, 1976). The multilayer COFs by RL-GEOPROF over the Arctic are within the ranges of

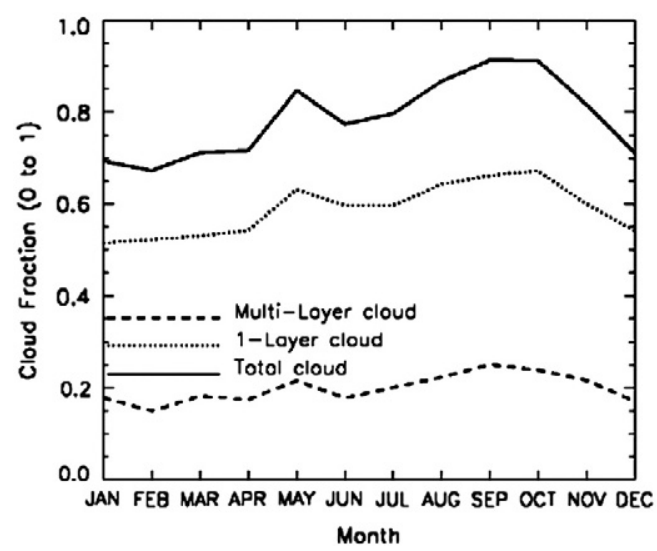

multi-layer COFs values reported in Heidinger and Pavolonis (2005); however, a separate layer is reported when at least an equivalent layer thickness of four resolution volumes, $960 \mathrm{~m}$, separates significant returns in a merged CPR-CALIOP profile. The layer separations of Arctic stratus are likely around several hundred meters. So, the multi-layer COF values reported in this study may be underestimated.

\subsection{Low-, middle-, and high-level cloud seasonal means and area averages}

Also of interest is the frequency of clouds by height. Surface-based observers cannot obtain accurate middle or high-level cloud distribution because of the constraints of existing low-level clouds. Satellite passive sensors are not capable of accurately determining lower layer cloud height when clouds overlap, and therefore cannot provide detailed middle or low-level cloud distribution. RL-GEOPROF data can

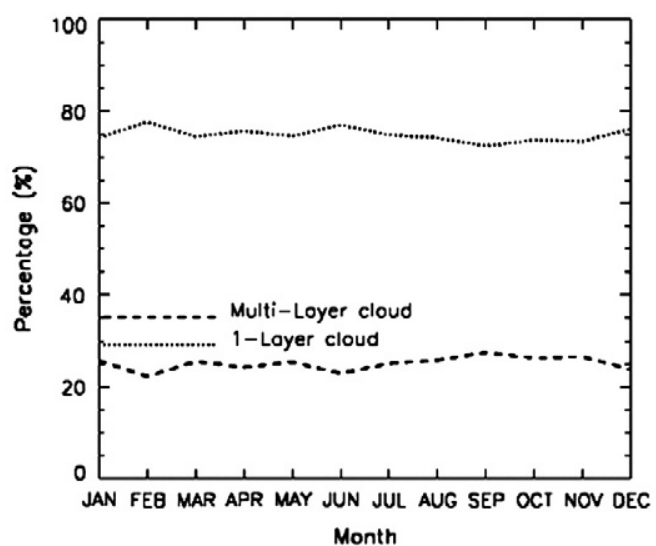

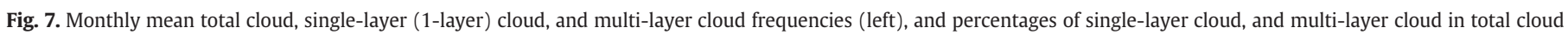
frequencies (right). 
provide detailed high-, middle-, and low-level cloud distribution by combining the advantages of radar and lidar observations.

For the ratio of seasonal mean low-level cloud frequency to total cloud frequency, values are high over the Arctic Ocean, and relatively low over Arctic land (Fig. 8). Over the ocean, the values are higher over the Atlantic side than over the Pacific side in winter and spring. The high ratios extend over the Kara Sea and Laptev Sea in summer. In autumn, high ratios are relatively evenly distributed over the ocean. Over the land on the Euro-Asia side, the values are high over northern Europe and decrease eastward; on the North American side, the values are high over the Canadian Archipelago and northern Canada and low over Alaska. The low values over Alaska and northeastern Russia may be partly due to the high surface elevation over those regions. For the seasonality, the ratio is lowest in summer and highest in autumn; this seasonality is more significant over land than over ocean.

For low-level COF, values are higher over ocean than over land (Fig. 9). However, the low-level COF over the Arctic Ocean except the Pacific side is comparable with that over the land. Over ocean, the values are much higher on the Atlantic side than over the Pacific side except in autumn, when both sides have relatively equally high values. Over land on the Euro-Asia side, the maximum values are over northern Europe and decrease eastward; on the North America side, the values are high over the Canada Archipelago and northern Canada and decrease closer to Alaska in all seasons except in winter, when they are similar. In autumn, low-level COF shows high values over the whole Arctic Ocean. In terms of the seasonality, low-level COF is lowest in summer and highest in autumn over both the Arctic Ocean and land.

For the ratio of middle-level cloud frequency to total cloud frequency, the values are lower over the Arctic Ocean than over the Arctic land (Fig. 10). Over the ocean, the values are comparable over the Atlantic side to those over the Pacific side in all seasons except summer and winter, when the values over the Pacific side are slightly higher. Over land on the Euro-Asia side, the values are low over northern Europe and increase eastward; on the North America side, the values are low over the Canada Archipelago and northern Canada and high over Alaska. In terms of seasonality, over the ocean, the values are relatively higher in winter than those in other seasons, with minimum values in summer.

For middle-level COF, values are lower over ocean than over land in every season except in winter, when the values are similar (figure not shown). Over ocean, the values are higher on the Atlantic side than over the Pacific side in all seasons except summer, when they are comparable. Over land on the Euro-Asia side, the values are evenly distributed; on the North America side, the values are much lower over the Canada Archipelago and northern Canada than over Alaska in all seasons. In terms of seasonality, the values are higher in autumn than those in other seasons over most regions except over Alaska, where values are relatively higher in summer and autumn than in other seasons. The values are at a minimum in summer over the ocean.

For the ratio of high-level cloud frequency to total cloud frequency, the values are lower over the Arctic Ocean than over the Arctic land (figure not shown). Over the ocean, the values are higher over the Atlantic side than over the Pacific side in all seasons except summer, when they are comparable. Over land on the Euro-Asia side, the values are relatively evenly distributed except in spring and summer when higher values appear over northeastern Russia; on the North America side, the values are low over the Canada Archipelago and northern Canada and high over Alaska.

For high-level COF, values are lower over ocean than over land except in winter, when values are similar (Fig. 11). Over ocean, the values are higher on the Atlantic side than over the Pacific side in all seasons except in summer, when both sides have similar values. Over land on the Euro-Asia side, the values are relatively evenly distributed except in winter when higher values appear over northern Europe and lower values over northeastern Russia; on the North America side, the values are much lower over the Canada Archipelago and northern Canada than over Alaska in all seasons.
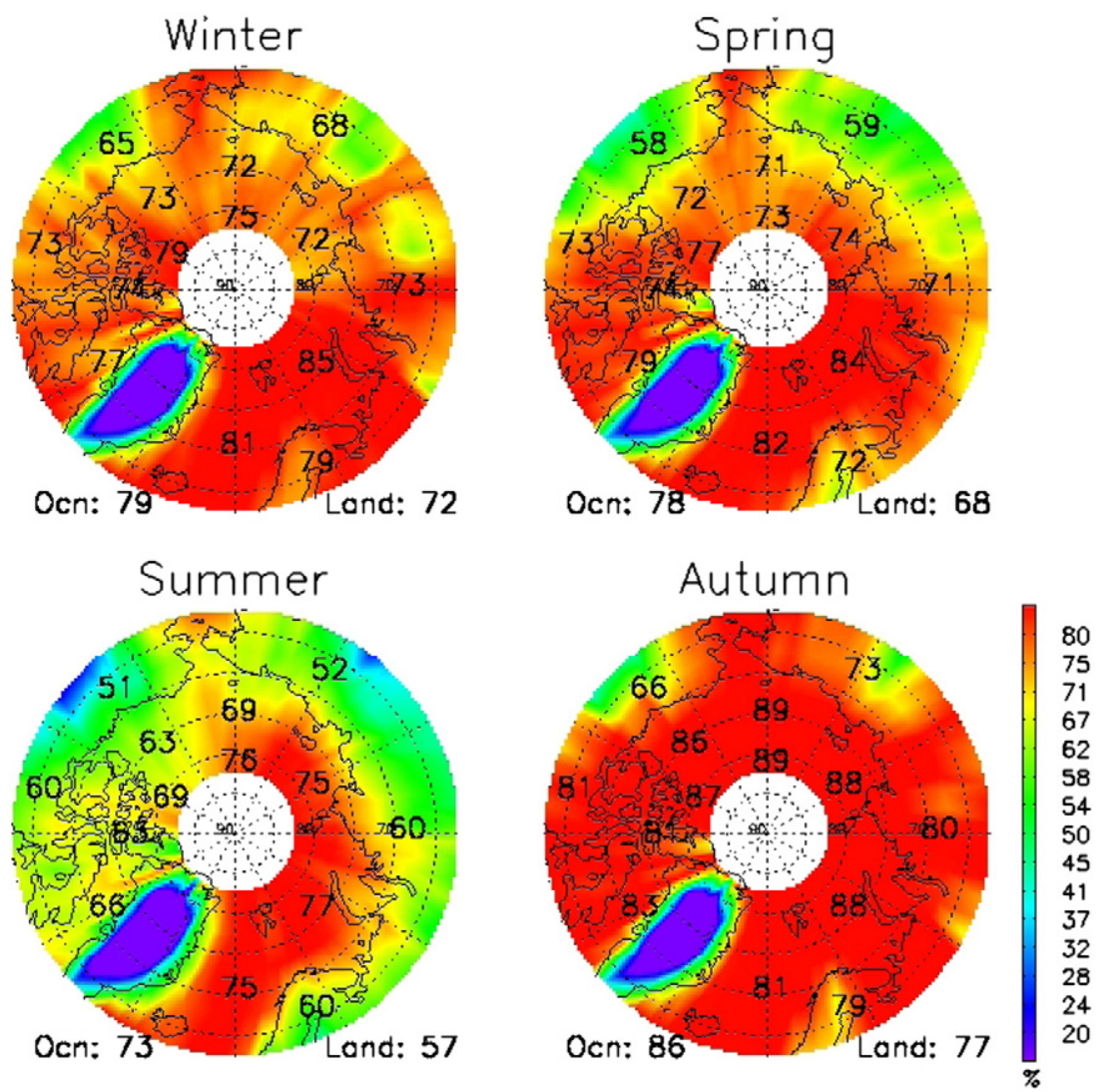

Fig. 8. Ratio of low-level cloud to total cloud frequencies in winter, spring, summer, and autumn from RL-GEOPROF from 2006 to 2011. 

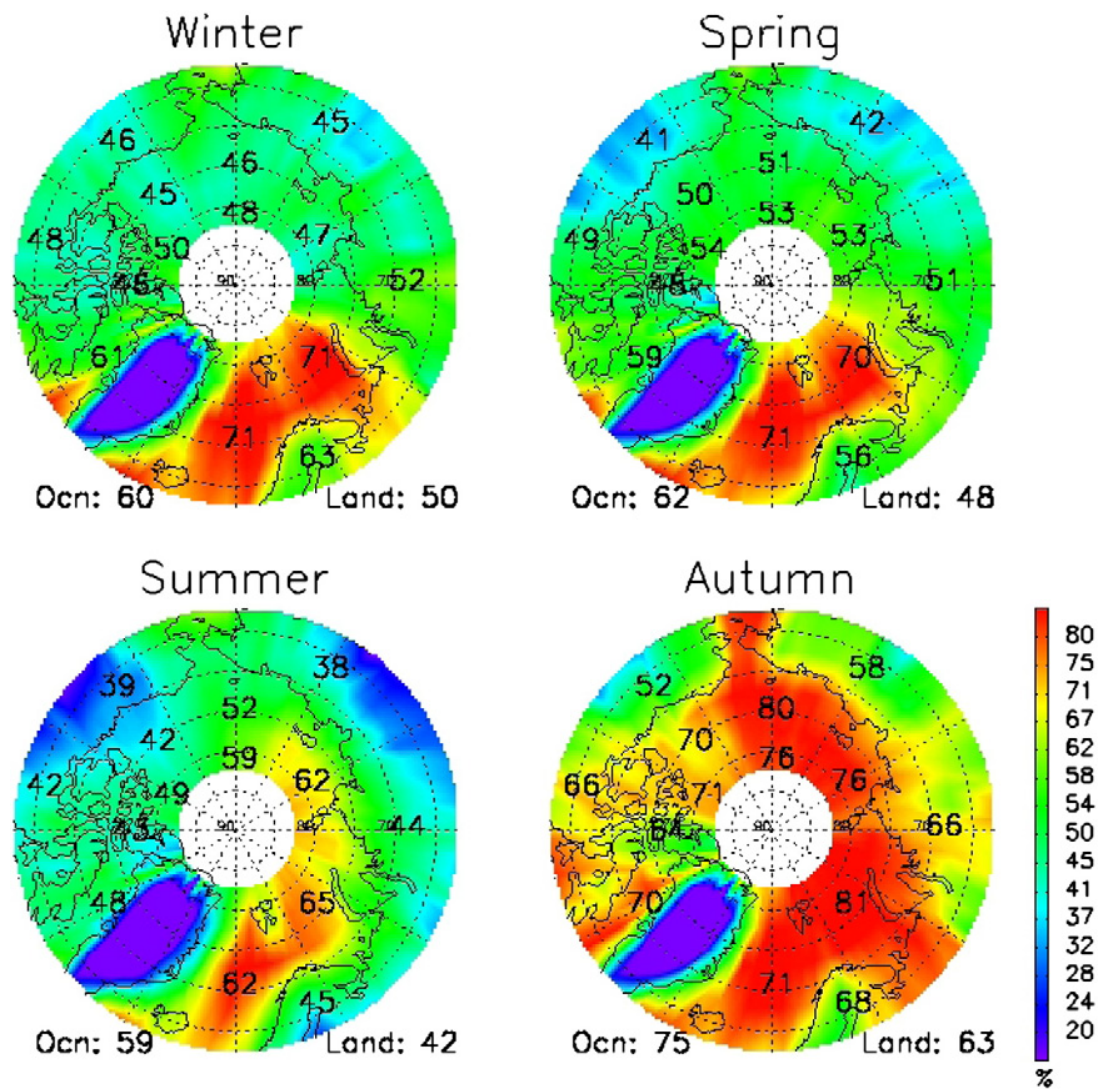

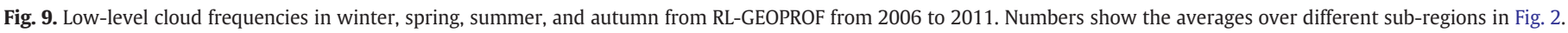
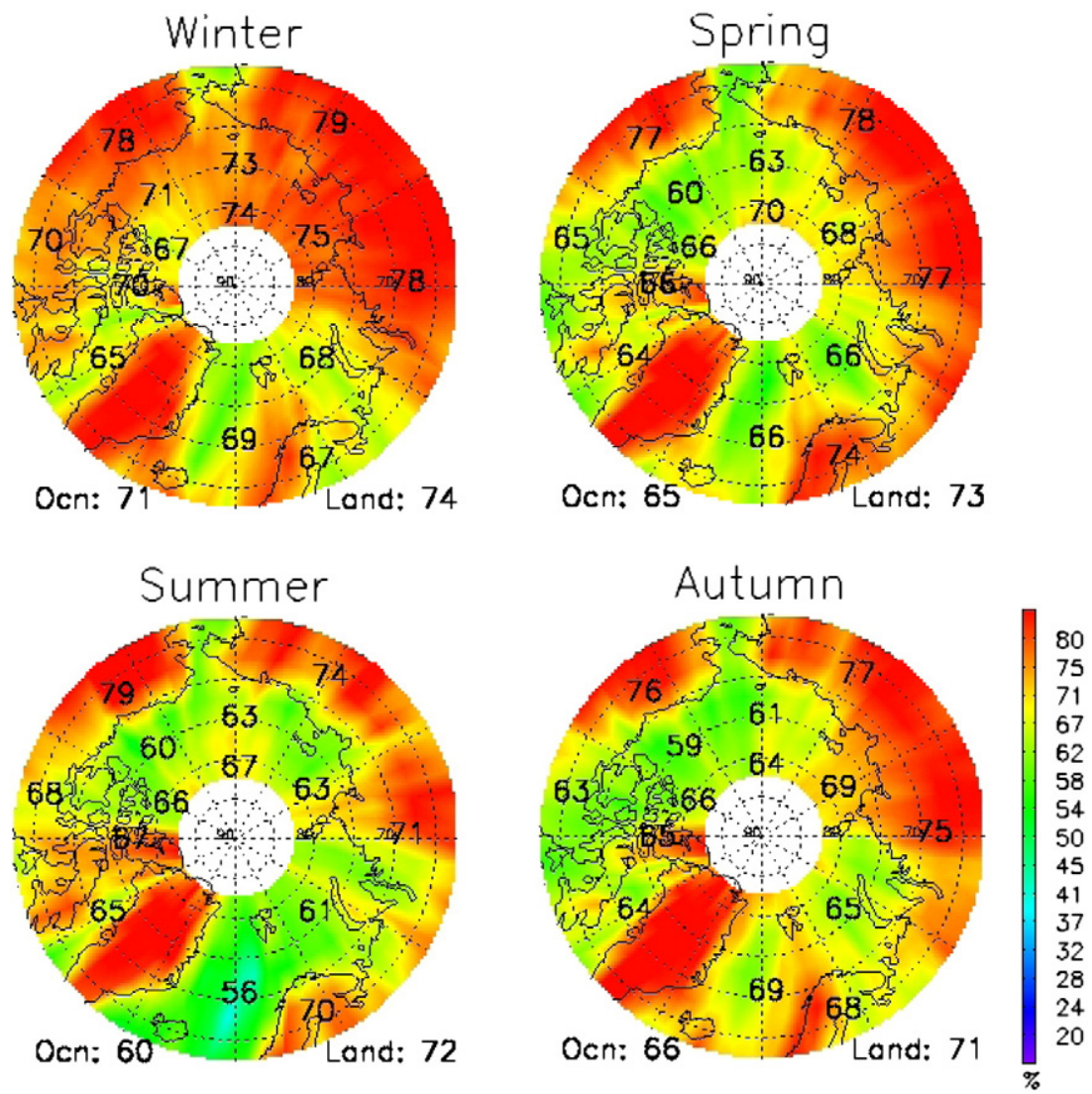

Fig. 10. Ratio of middle-level cloud to total cloud frequencies in winter, spring, summer, and autumn from RL-GEOPROF from 2006 to 2011. 

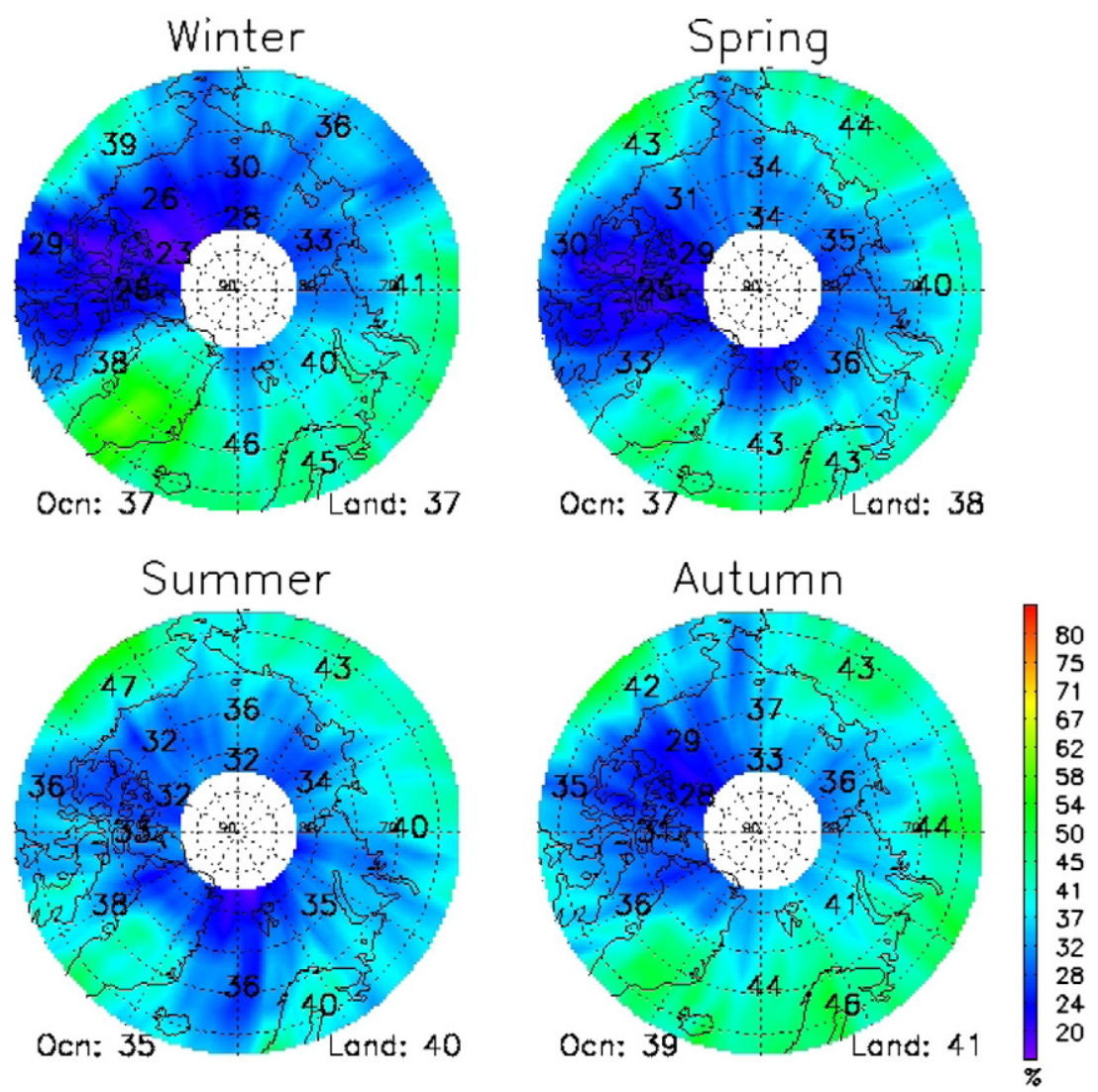

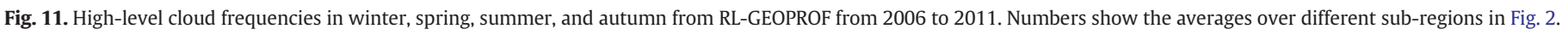

Over the central Arctic Ocean, low-level COFs have higher values than middle-level, and high-level COFs have the lowest values. Lowlevel COFs follow the annual cycle of total clouds; middle-level COFs have relatively constant values, with higher values from July to November. High-level COFs are relatively constant throughout the year (Fig. 12). Percentages of low-level (middle-level, high-level) COFs to the total COFs are around $82 \%$ (64\%, 41\%) throughout the year.

It should be noted that the merged CloudSat and CALIPSO product may perform better in describing the low-level COF than the passive satellite sensors because of the better detection capability in the presence of higher-level cloud. However, the surface contamination in the CloudSat observations prevents a comprehensive description of lowlevel COF from this merged data set. The RL-GEOPROF does not include the clouds near the surface that can only detected by CloudSat, but with non-negligible surface contamination. Low-level COFs are likely underestimated because of these limitations. Caution should be taken when comparing the low-level COF from this merged data set with those from other data sets and model outputs.

\subsection{PDFs of cloud top height, and base height}

Cloud top and bottom heights are key parameters in determining the cloud radiative effect at the top of the atmosphere and surface by influencing the longwave radiation. For example, in a subarctic standard atmosphere, downward longwave irradiance increases by nearly $10 \%$ when the base height of an optically thick cloud changes from $5 \mathrm{~km}$ to $1 \mathrm{~km}$ (Kato et al., 2010). Changes in these distributions may also respond and feedback to changes in climate. Signals from passive sensors
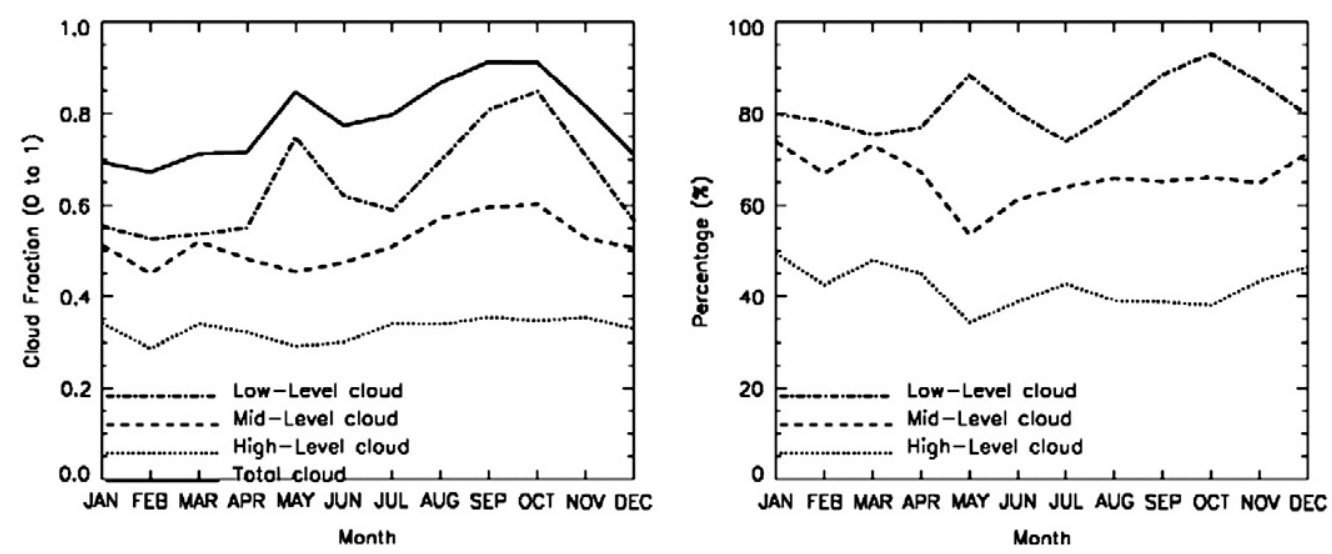

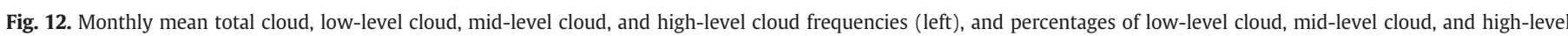
cloud in total cloud frequencies (right). 
in visible and infrared channels are mainly from the top portion of the top cloud layer, making the retrieval of cloud information underneath inaccurate. Cloud top height is usually underestimated by $1 \mathrm{~km}$ or more compared to that determined by active sensors (Holz et al., 2008; Minnis et al., 2008b). Cloud bottom height, middle and low level cloud distribution, and cloud thickness cannot be determined from such observations. Furthermore, clouds with different cloud top and bottom heights tend to be different types of clouds. For example, clouds with top higher than $6000 \mathrm{~m}$ are more likely to be cirrus, and clouds with bottom lower than $2000 \mathrm{~m}$ are more likely to be stratus. In this section, probability density function (PDFs) of cloud base height, and cloud top height are calculated over every box and over each Arctic sub-region. Appendix A gives the derivation of the cloud top height PDFs. Spatial distributions of these PDFs cannot be as easily shown as COFs. Therefore, only PDFs over the central Arctic Ocean are shown.

PDFs of cloud top height in relative frequency show a bimodal distribution with one peak of cloud top height in the lower troposphere and another peak of cloud top height in the upper troposphere in all four seasons (Fig. 13). The cloud top height with the maximum relative frequency in the lower troposphere is between a range of 600 and $1200 \mathrm{~m}$. In the upper troposphere, the cloud top height with the maximum relative frequencies is between a range of 7000 and $9000 \mathrm{~m}$. There is a possible seasonal variation in the altitude of these two peaks. This bimodal distribution can also be seen in the monthly PDFs of cloud top heights from CALIOP VFM in January 2011 over the Arctic Ocean (not shown), and in Fig. 8 of Intrieri et al. (2002), in March, April, June, July, August, October, and November. Tjernström et al. (2008) showed a relative maximum frequency of highest cloud tops near $7 \mathrm{~km}$ in model outputs. This maximum frequency of cloud top heights around 7 to $9 \mathrm{~km}$ over the Arctic Ocean may be related to the tropopause height. Based on the North Pole drifting station aerological data, Nagurny (1998) showed the tropopause lower boundary varies between 8 and $10 \mathrm{~km}$ during the year over the Arctic Basin, with the major and the second maximum values in August and December, and the major and the second minimum values in April and October. The cloud top heights with the maximum PDFs in the upper troposphere are relatively higher in summer and lower in spring, which is consistent with the tropopause lower boundary annual evolution. The formation, persistence, dissipation, and its radiative effect of the clouds with top heights near the tropopause lower boundary are not well studied, and need further investigation.

The PDFs of cloud base height in relative frequency show relatively high values for cloud base below $1000 \mathrm{~m}$, with the maximum values below $200 \mathrm{~m}$. The relative frequency decreases quickly with altitude higher than $1500 \mathrm{~m}$ in all seasons (Fig. 14). The PDFs between $1000 \mathrm{~m}$ and $1500 \mathrm{~m}$ are higher in summer than those in other seasons because of elevated cloud bases in summer. Clouds with base heights lower than $2000 \mathrm{~m}$ account for $72 \%, 75 \%, 74 \%$, and $87 \%$ of all clouds, which is consistent with the finding that boundary layer clouds are prevalent throughout the year (Intrieri et al., 2002), and decreasing sea ice leads to increasing boundary layer cloud due to the enhanced surface evaporation in autumn (Wu and Lee, in press).

PDFs of cloud base height from RL-GEOPROF have limitations in accuracy due to the attenuation of lidar and surface contamination of CloudSat. Clouds near the surface that can only be detected by CloudSat but with a non-negligible surface contamination are not
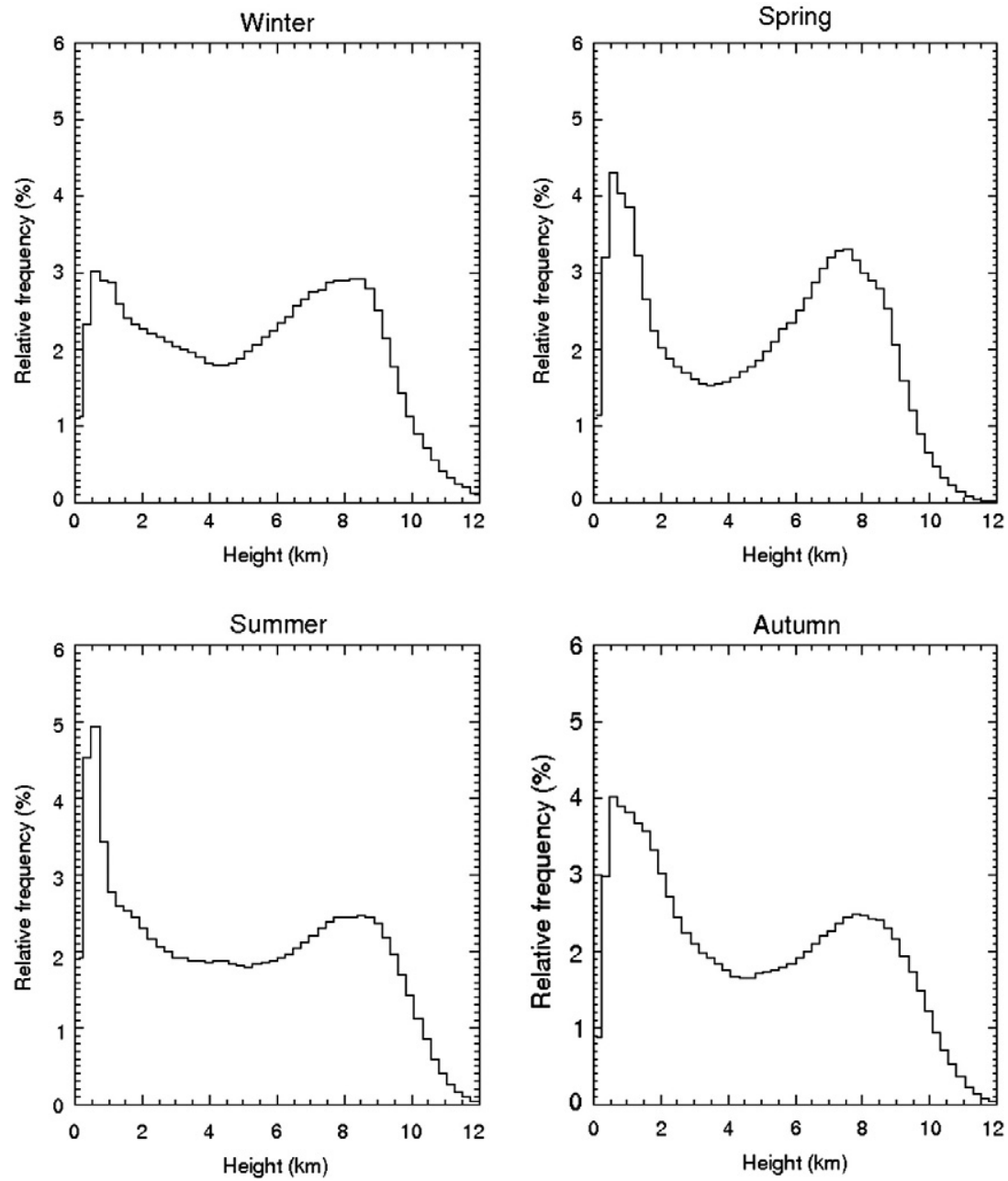

Fig. 13. Cloud top height probability density function over the central Arctic Ocean in winter, spring, summer, and autumn with a bin size of $240 \mathrm{~m}$. 

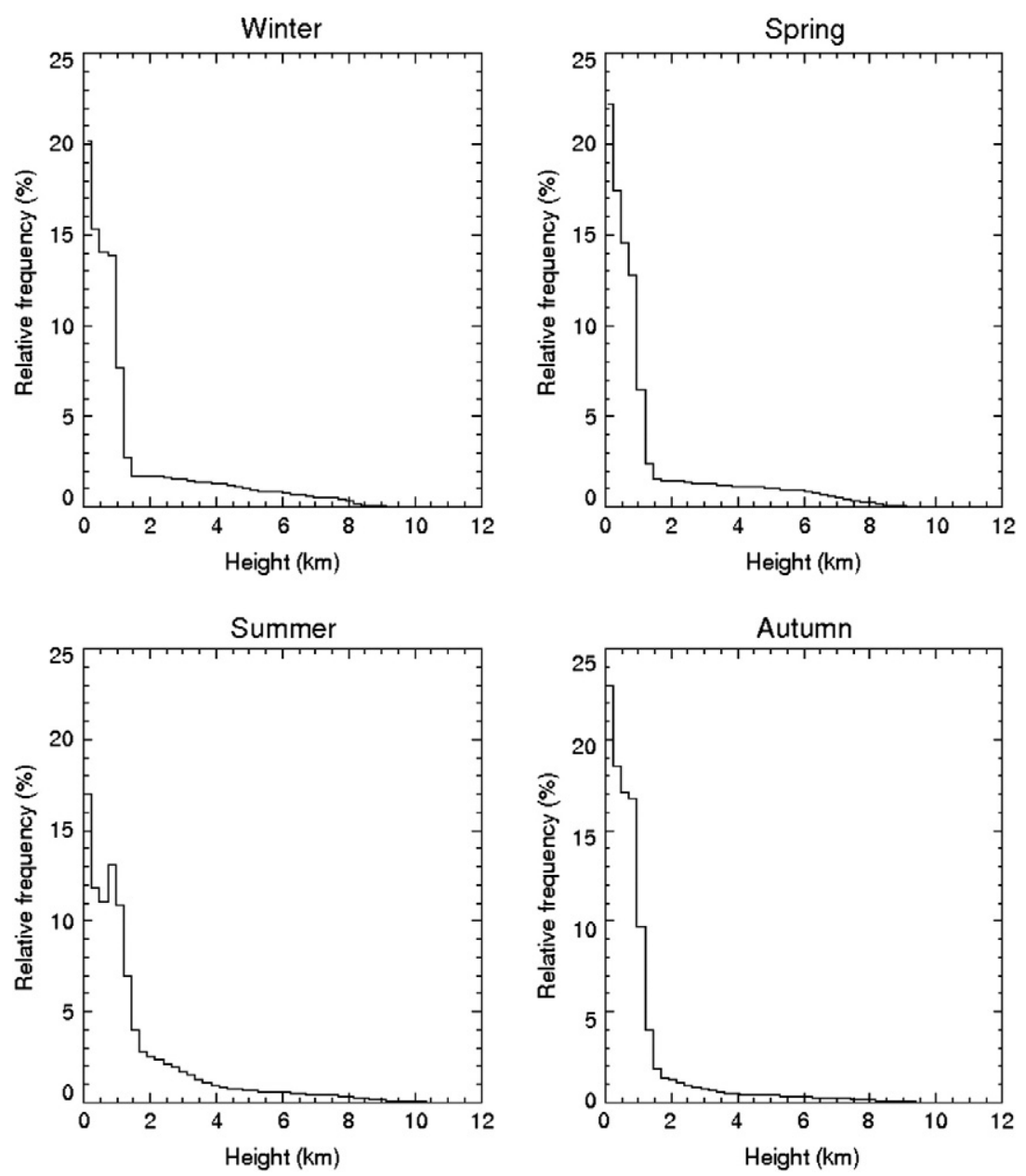

Fig. 14. Cloud base height probability density function over the central Arctic Ocean in winter, spring, summer, and autumn with a bin size of $240 \mathrm{~m}$.

counted due to the surface contamination. As a result, the cloud base height PDFs near the surface are likely underestimated, though the PDF values near the surface are high. The sample numbers of cloud with base height less than $60 \mathrm{~m}$ are assigned a value of 0 in the PDFs in order to remove any possible surface contamination in the CALIPSO data. Cloud base height PDFs from surface-based active sensors are expected to be more accurate (Intrieri et al., 2002; Shupe et al., 2011).

\section{Discussion and conclusion}

This study presents an analysis of Arctic clouds based on the RLGEOPROF product, which contains cloud vertical profiles by combining active lidar observations from CALIOP onboard CALIPSO and active radar observations from CPR onboard CloudSat.

Combined lidar and radar onboard satellite observations of clouds in the Polar Regions has advantages and disadvantages compared to passive satellite observations in the more traditional visible and infrared bands. In the Polar Regions, passive satellite sensors have challenges in detecting clouds due to the weak contrast between clouds and the underlying surface, especially at nighttime, and they are not sensitive to optically thin clouds. For example, MODIS detects few clouds with optical depths less than 0.4 (Ackerman et al., 2008). Combined CloudSat and CALIPSO observations have the capability of detecting thin cirrus with optical depths of 0.01 or less (Vaughan et al., 2009) and have better detection capability at nighttime than passive approaches. Clouds with optical depths less than 0.3 detected by CALIPSO comprise slightly more than $19 \%$ of all clouds, with nearly $70 \%$ of those thin clouds having optical depths less than 0.1 (Minnis et al., 2008a). The higher cloud amount from
RL-GEOPROF throughout most of the year, except June, July, and August (Fig. 1), might be due to the higher sensitivity of radar/lidar observations to thin clouds, and better detection capability at night. Liu et al. (2010) showed that CloudSat/CALIPSO detects more clouds in the Arctic than MODIS for both daytime and nighttime scenes, and this difference increases with increasing sea ice concentration. The higher sensitivity of RL-GEOPROF to thin clouds might also explain the lack of an April cloud minimum seen in other datasets. There is a relatively high frequency of ice crystal precipitation ("diamond dust") in late winter/early spring, which passive satellite sensors and surface observers may not detect (Curry et al., 1996). Intrieri et al. (2002) reported higher cloud amounts from June to August over the Arctic Ocean than those shown in Fig. 1. Kay et al. (2008) showed reduced cloud amounts over the Western Arctic Ocean from June to August and attribute this to an anticyclone pattern; the same negative cloud anomaly appeared again in July 2011 (Overland et al., 2011). It remains to be seen if this lower cloud amount from June to August shown in RL-GEOPROF from 2006 to 2011 (Fig. 1) will persist in the future. In June, July, and August, MODIS sees more clouds than RL-GEOPROF due partially to the availability of visible observations, and larger IFOV and swath width (Ackerman et al., 2008).

Seasonal mean COFs show higher cloud amounts on the Atlantic side of the Arctic Ocean than on the Pacific side. Over the Arctic Ocean, the seasonal mean COFs have the minimum value in winter, maximum in autumn, with moderate amounts in spring and summer. Higher COFs on the Atlantic side of the Arctic Ocean are related to the frequent synoptic activities and high atmospheric humidity and temperature over the open water (Serreze and Barry, 2005). The low COFs in winter over the central Arctic Ocean, Canadian Archipelago, and east-central Asia are likely related to the strong anticyclones over those regions 
and lack of moisture. The seasonal cycle of low-level clouds resembles the total cloud seasonal cycle most, and high-level clouds are relatively constant during the year as shown in Fig. 12. Low-level cloud amounts over the Arctic Ocean are low in winter, and begin to increase in spring and stay high during the melting season. Herman and Goody (1976) attributed this seasonality to the radiative and diffusive cooling of relatively warm and moist continental air over the pack ice. Curry and Herman (1985) found an association between low-level clouds and low level moisture advection, radiative cooling and boundary layer turbulence, while midlevel clouds are associated with large-scale transport of heat and moisture. Beesley and Moritz (1999) suggested that microphysical processes related to atmospheric ice are the key factors that control low-level cloud amount seasonality over the Arctic Ocean.

RL-GEOPROF data used in this study are from July 2006 to March 2011. Sea ice extent and concentration during this period were at record lows since the satellite era began. Increasingly large open water areas lead to higher cloud cover because of the greater water vapor supply from the open water surface, the accumulated evaporation beginning in summer (Liu et al., 2012; Wu and Lee, 2012), and the decreased lower tropospheric stability (Schweiger et al., 2008b). It is not surprising to see higher than average COF over the central Arctic Ocean in autumn as well as in spring compared to cloud amount climatologies from other satellite datasets, given the more recent time period examined in this study.

The ratios of low-level cloud to total cloud are lowest in summer, and highest in autumn over both ocean and land. Arctic surface temperature inversions are strongest in winter, weakening in spring and summer and becoming strong again in autumn (Serreze et al., 1992). This indicates that Arctic lower atmospheric static stability is strongest in winter and weakest in summer. The seasonality of low-level COFs to total cloud might be correlated to the static stability seasonality, as the stronger static stability in winter is more favorable for keeping the cloud in the low level than in summer, when cloud top tends to extend to the middle or even high level due to the weak static stability. However, this does not explain the maximum ratio in autumn, when static stability is not as strong as that in winter. The ratios of low-level cloud to total cloud over ocean are higher than those over land in all seasons except winter, when values are comparable over the Atlantic side of the Arctic Ocean and over the land. The ratios of middle-level and highlevel clouds to total cloud over ocean are lower over ocean. The higher low-level cloud to total cloud ratio over ocean and lower ratio over land contrast might be due to the stronger static stability over ocean in spring and summer, and higher surface elevation over land. Relatively more convective processes over the land due to the surface heating, especially in spring and summer, and higher surface elevation over land might contribute to the middle-level and high-level cloud seasonality.

Cloud radiative forcing on the surface depends not only on the cloud macrophysical properties, but also the microphysical properties, including vertical distributions of cloud phase, cloud particle size, particle concentration, and particle habit. A vertical profile of cloud optical thickness calculated from these microphysical properties is essential to study cloud effects on the surface and in the Arctic climate system. A climatology of these properties is the subject of future work.

\section{Acknowledgments}

The authors would like to thank the CloudSat data processing center at Colorado State University for providing the CloudSat/CALIPSO product 2B-GEOPROF-lidar data, and Goddard Space Flight Center at NASA for providing the MODIS data. We thank Ralph Kuehn for discussions regarding the CALIPSO and CloudSat data. This work was supported in part by the National Oceanic and Atmospheric Administration's (NOAA) Climate Data Records program. The views, opinions, and findings contained in this report are those of the author(s) and should not be construed as an official National Oceanic and Atmospheric Administration or U.S. Government position, policy, or decision.

\section{Appendix A}

There is a significant sample count spike at layers around $8.2 \mathrm{~km}$ in altitude for all seasons, and a sample count drop at layers above $8.2 \mathrm{~km}$, as seen in an example over the Arctic Ocean (defined as the region between 75 and $85^{\circ} \mathrm{N}$ latitude, and 0 and $240^{\circ}$ longitude), (Fig. A1). This spike and drop is a coincidence with changes in horizontal and vertical resolutions in CALIOP data, with $333 \mathrm{~m}(1 \mathrm{~km})$ in horizontal resolution and $30 \mathrm{~m}(60 \mathrm{~m})$ in vertical resolution below (above) $8.2 \mathrm{~km}$. Such spikes and drops in cloud top height sample counts are not as dramatic in the CALIOP product as in the RLGEOPROF. Eliminating all these cases would reduce the seasonal total cloud COFs by less than $2 \%$ over ocean and land in all seasons. With the assumption that there should not be a discontinuity in the cloud top height sample counts around $8.2 \mathrm{~km}$ and the constraint of no change in the total cloud sample counts, the following steps show how adjustments are made to remove the spikes and the drops in the top cloud height sample counts. (1) Calculate the ratio (A) of cloud top height sample count at the layer just below the layers with the spike to that at the layer just above the layers with the spike. (2) Set the cloud top height sample counts at the layers with the spike the same as that at the layer just below the layers with the spike. (3) Adjust the cloud top height sample counts at the layer just above the layers with the spike equal to that at the layer just below the layers with the spike by multiplying the ratio (A). (4) Adjust the cloud top height sample counts for other layers above the layers with the spike by multiplying ratio (A) with a damping factor, with the constraint that the total added sample counts equal to the reduced sample counts by the removal of the spike in step 2 . The cloud top height sample counts as a function of the cloud top height after the adjustment is shown in Fig. A2. PDFs of cloud top height (Fig. 13) are then derived based on Fig. A2.
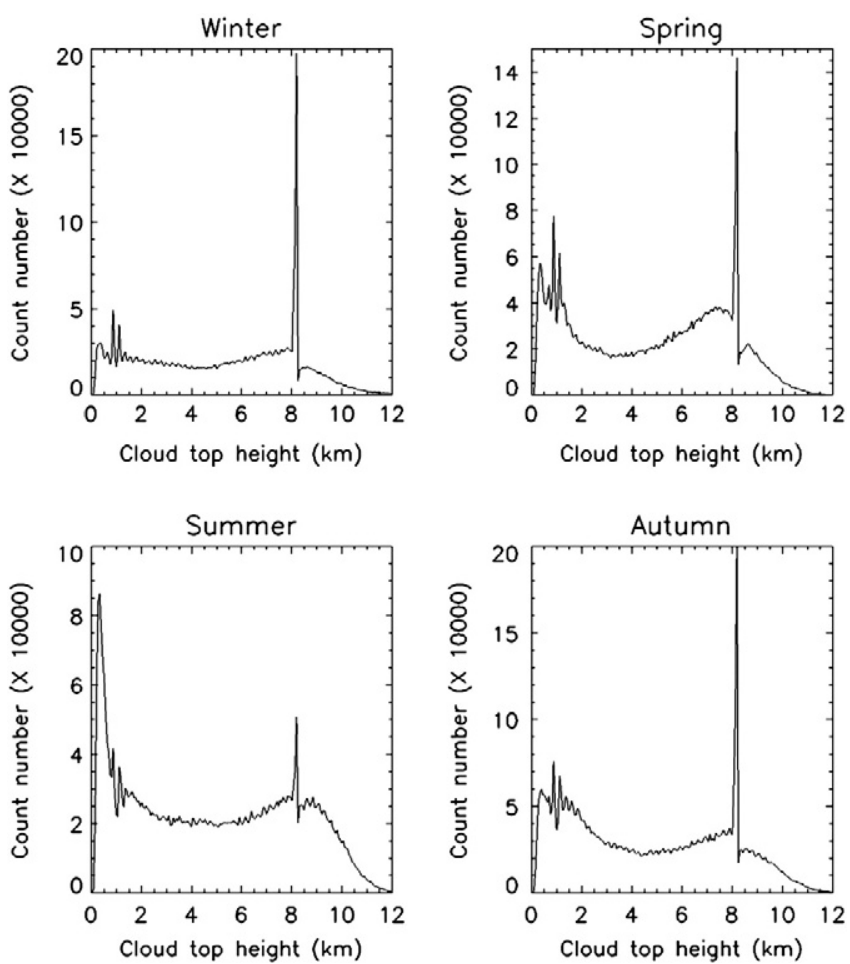

Fig. A1. Cloud top height sample counts as a function of cloud top height with a bin size of $60 \mathrm{~m}$ over the Arctic Ocean (region between 75 and $85^{\circ} \mathrm{N}$ latitude, and 0 and $240^{\circ}$ longitude) using cloud covered footprint from the RL-GEOPROF from July 2006 to March 2011. 

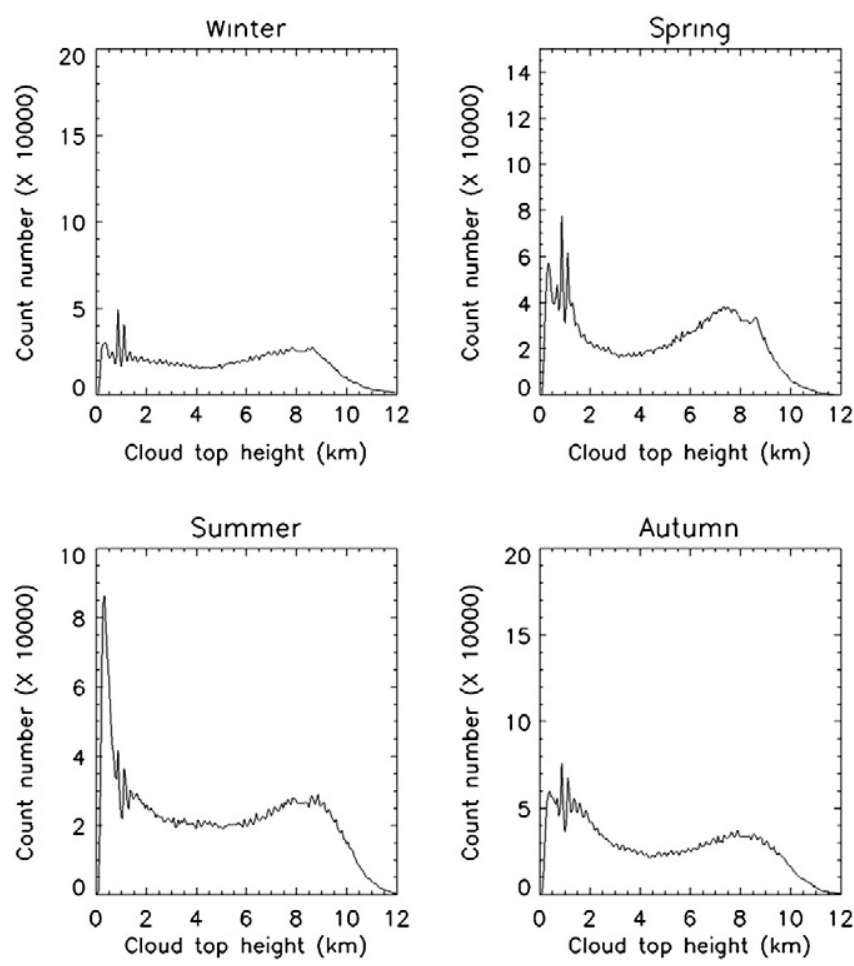

Fig. A2. Same as Fig. A1, except after adjustments.

\section{References}

Ackerman, S. A., Holz, R. E., Frey, R., Eloranta, E. W., Maddux, B. C., \& McGill, M. (2008). Cloud detection with MODIS. Part II: Validation. Journal of Atmospheric and Oceanic Technology, 25, 1073-1086.

Ackerman, S. A., Strabala, K. I., Menzel, W. P., Frey, R. A., Moeller, C. C., \& Gumley, L. E. (1998). Discriminating clear sky from clouds with MODIS. Journal of Geophysical Research - Atmospheres, 103, 32141-32157.

Beesley, J. A., \& Moritz, R. E. (1999). Toward an explanation of the annual cycle of cloudiness over the Arctic Ocean. Journal of Climate, 12, 395-415.

Birch, C. E., Brooks, I. M., Tjernström, M., Milton, S. F., Earnshaw, P., Soderberg, S., et al. (2009). The performance of a global and mesoscale model over the central Arctic Ocean during late summer. Journal of Geophysical Research - Atmospheres, 114, D13104.

Curry, J., Ebert, E., \& Herman, G. (1988). Mean and turbulence structure of the summertime Arctic cloudy boundary-layer. Quarterly Journal of the Royal Meteorological Society, 114, 715-746.

Curry, J., \& Herman, G. (1985). Relationships between large-scale heat and moisture budgets and the occurrence of Arctic stratus clouds. Monthly Weather Review, $113,1441-1457$.

Curry, J. A., Rossow, W. B., Randall, D., \& Schramm, J. L. (1996). Overview of Arctic cloud and radiation characteristics. Journal of Climate, 9, 1731-1764.

Devasthale, A., Tjernström, M., Karlsson, K., Thomas, M. A., Jones, C., Sedlar, J., et al. (2011). The vertical distribution of thin features over the Arctic analysed from CALIPSO observations Part I: Optically thin clouds. Tellus Series B: Chemical and Physical Meteorology, 63, 77-85.

Dong, X., Xi, B., Crosby, K., Long, C. N., Stone, R. S., \& Shupe, M. D. (2010). A 10 year climatology of Arctic cloud fraction and radiative forcing at Barrow, Alaska. Journal of Geophysical Research - Atmospheres, 115, D17212.

Eastman, R., \& Warren, S. G. (2010). Interannual variations of Arctic cloud types in relation to sea ice. Journal of Climate, 23, 4216-4232.

Ebert, E. E. (1989). Analysis of polar clouds from satellite imagery using patternrecognition and a statistical cloud analysis scheme. Journal of Applied Meteorology, $28,382-399$.

Eloranta, E. W., Garcia, J. P., Razenkov, I. A., Uttal, T., \& Shupe, M. (2008). Cloud fraction statistics derived from 2-years of high spectral resolution lidar data acquired at Eureka, Canada. 24th International Laser Radar Conference June 23-27, 2008, Boulder, Colorado.

Francis, J. A., White, D. M., Cassano, J. J., Gutowski, W. J., Jr., Hinzman, L. D., Holland, M. M., et al. (2009). An Arctic hydrologic system in transition: Feedbacks and impacts on terrestrial, marine, and human life. Journal of Geophysical Research - Biogeosciences, 114, G04019.

Frey, R. A., Ackerman, S. A., Liu, Y., Strabala, K. I., Zhang, H., Key, J. R., et al. (2008). Cloud detection with MODIS. Part I: Improvements in the MODIS cloud mask for collection 5 RID F-5597-2010. Journal of Atmospheric and Oceanic Technology, 25, 1057-1072.

Gao, B. C., Han, W., Tsay, S. C., \& Larsen, N. F. (1998). Cloud detection over the Arctic region using airborne imaging spectrometer data during the daytime. Journal of Applied Meteorology, 37, 1421-1429.
Hahn, C. J., \& Warren, S. G. (2003). Cloud climatology for land stations worldwide, 1971-1996. Numerical data package NDP-026D. Oak Ridge, Tennessee: Carbon Dioxide Information Analysis Center (CDIAC), Department of Energy (Documentation, 35 pages).

Hahn, C. J., \& Warren, S. G. (2007). A gridded climatology of clouds over land (1971-96) and ocean (1954-97) from surface observations worldwide. NDP-026E. Oak Ridge, TN: Carbon Dioxide Information Analysis Center, Oak Ridge National Laboratory (documentation, 71 pp.).

Hahn, C. J., Warren, S. G., \& London, J. (1995). The effect of moonlight on observation of cloud cover at night, and application to cloud climatology. Journal of Climate, 8 , 1429-1446.

Heidinger, A., \& Pavolonis, M. (2005). Global daytime distribution of overlapping cirrus cloud from NOAA's Advanced Very High Resolution Radiometer RID F-5591-2010 RID F-5618-2010. Journal of Climate, 18, 4772-4784.

Herman, G., \& Goody, R. (1976). Formation and persistence of summertime Arctic stratus clouds. Journal of the Atmospheric Sciences, 33, 1537-1553.

Holz, R. E., Ackerman, S. A., Nagle, F. W., Frey, R., Dutcher, S., Kuehn, R. E., et al. (2008) Global Moderate Resolution Imaging Spectroradiometer (MODIS) cloud detection and height evaluation using CALIOP. Journal of Geophysical Research - Atmospheres, 113, D00A19.

Im, E., Durden, S. L., \& Tanelli, S. (2006). CloudSat: The cloud profiling radar mission. Proceedings of 2006 CIE International Conference on Radar 1302; (o.2)1302-5 vol.25 vol.2; 50.2 .

Inoue, T. (1987). A cloud type classification with NOAA 7 split-window measurements. Journal of Geophysical Research - Atmospheres, 92, 3991-4000.

Inoue, J., Liu, J., Pinto, J. O., \& Curry, J. A. (2006). Intercomparison of Arctic regional climate models: Modeling clouds and radiation for SHEBA in May 1998. Journal of Climate, 19, 4167-4178.

Intrieri, J. M., Fairall, C. W., Shupe, M. D., Persson, P. O. G., Andreas, E. L., Guest, P. S., et al. (2002). An annual cycle of Arctic surface cloud forcing at SHEBA. Journal of Geophysical Research - Oceans, 107, 8039.

Kato, S., Sun-Mack, S., Miller, W. F., Rose, F. G., Chen, Y., Minnis, P., et al. (2010). Relationships among cloud occurrence frequency, overlap, and effective thickness derived from CALIPSO and CloudSat merged cloud vertical profiles RID G-1902-2010. Journal of Geophysical Research - Atmospheres, 115, D0OH28.

Kay, J. E., \& Gettelman, A. (2009). Cloud influence on and response to seasonal Arctic sea ice loss. Journal of Geophysical Research - Atmospheres, 114, D18204.

Kay, J. E., L'Ecuyer, T., Gettelman, A., Stephens, G., \& O'Dell, C. (2008). The contribution of cloud and radiation anomalies to the 2007 Arctic sea ice extent minimum. Geophysical Research Letters, 35, L08503.

Key, J. (1990). Cloud cover analysis with Arctic Advanced Very High-Resolution Radiometer data. 2. Classification with spectral and textural measures. Journal of Geophysical Research - Atmospheres, 95, 7661-7675.

Key, J., \& Barry, R. G. (1989). Cloud cover analysis with Arctic AVHRR data .1. Cloud detection. Journal of Geophysical Research - Atmospheres, 94, 18521-18535.

Liu, Y., Ackerman, S. A., Maddux, B. C., Key, J. R., \& Frey, R. A. (2010). Errors in cloud detection over the Arctic using a satellite imager and implications for observing feedback mechanisms. Journal of Climate, 23, 1894-1907.

Liu, Y., Key, J. R., Francis, J. A., \& Wang, X. (2007). Possible causes of decreasing cloud cover in the Arctic winter, 1982-2000. Geophysical Research Letters, 34, L14705.

Liu, Y. H., Key, J. R., Frey, R. A., Ackerman, S. A., \& Menzel, W. P. (2004). Nighttime polar cloud detection with MODIS. Remote Sensing of Environment, 92, 181-194.

Liu, Y., Key, J. R., Liu, Z., Wang, X., \& Vavrus, S. J. (2012). A cloudier Arctic expected with diminishing sea ice. Geophysical Research Letters, 39, L05705. http://dx.doi.org/10. 1029/2012GL051251.

Liu, Y., Key, J. R., \& Wang, X. (2008). The influence of changes in cloud cover on recent surface temperature trends in the Arctic. Journal of Climate, 21, 705-715.

Liu, Y., Key, J. R., \& Wang, X. (2009). Influence of changes in sea ice concentration and cloud cover on recent Arctic surface temperature trends. Geophysical Research Letters, 36, L20710.

Lubin, D., \& Morrow, E. (1998). Evaluation of an AVHRR cloud detection and classification method over the central Arctic Ocean. Journal of Applied Meteorology, 37, 166-183.

Mace, G. G., Zhang, Q., Vaughan, M., Marchand, R., Stephens, G., Trepte, C., et al. (2009). A description of hydrometeor layer occurrence statistics derived from the first year of merged CloudSat and CALIPSO data. Journal of Geophysical Research - Atmospheres, 114, D00A26.

Marchand, R., Mace, G. G., Ackerman, T., \& Stephens, G. (2008). Hydrometeor detection using CloudSat - An earth-orbiting 94-GHz cloud radar. Journal of Atmospheric and Oceanic Technology, 25, 519-533.

Minnis, P., Chakrapani, V., Doelling, D. R., Nguyen, L., Palikonda, R., Spangenberg, D. A. et al. (2001). Cloud coverage and height during FIRE ACE derived from AVHRR data. Journal of Geophysical Research - Atmospheres, 106, 15215-15232.

Minnis, P., Trepte, Q. Z., Sun-Mack, S., Chen, Y., Doelling, D. R., Young, D. F., et al. (2008). Cloud detection in nonpolar regions for CERES using TRMM VIRS and Terra and Aqua MODIS data RID G-1902-2010. IEEE Transactions on Geoscience and Remote Sensing, 46, 3857-3884.

Minnis, P., Yost, C. R., Sun-Mack, S., \& Chen, Y. (2008). Estimating the top altitude of optically thick ice clouds from thermal infrared satellite observations using CALIPSO data RID G-1902-2010. Geophysical Research Letters, 35, L12801.

Nagurny, A. (1998). Climatic characteristics of the tropopause over the Arctic Basin. Annales Geophysicae - Atmospheres Hydrospheres and Space Sciences, 16, 110-115.

Overland, J., Bhatt, U., Key, J., Liu, Y., \& Wang, M. (2011). Temperature and clouds [in Arctic Report Card 2011]. http://www.arctic.noaa.gov/reportcard

Quinn, P. K., Shaw, G., Andrews, E., Dutton, E. G., Ruoho-Airola, T., \& Gong, S. L. (2007) Arctic haze: Current trends and knowledge gaps. Tellus Series B: Chemical and Physical Meteorology, 59, 99-114. 
Rossow, W. B., \& Schiffer, R. A. (1999). Advances in understanding clouds from ISCCP. Bulletin of the American Meteorological Society, 80, 2261-2287.

Schweiger, A. J., Lindsay, R. W., Key, J. R., \& Francis, J. A. (1999). Arctic clouds in multiyear satellite data sets. Geophysical Research Letters, 26, 1845-1848.

Schweiger, A. J., Lindsay, R. W., Vavrus, S., \& Francis, J. A. (2008). Relationships between Arctic sea ice and clouds during autumn. Journal of Climate, 21, 4799-4810.

Schweiger, A. J., Zhang, J., Lindsay, R. W., \& Steele, M. (2008). Did unusually sunny skies help drive the record sea ice minimum of 2007? Geophysical Research Letters, 35, L10503.

Serreze, M. C., \& Barry, R. G. (2005). The Arctic climate system. : Cambridge University Press.

Serreze, M. C., Kahl, J. D., \& Schnell, R. C. (1992). Low-level temperature inversions of the Eurasian Arctic and comparisons with Soviet drifting station data. Journal of Climate, 5, 615-629.

Shupe, M. D., Walden, V. P., Eloranta, E. Uttal, T, Campbell, J. R., Starkweather, S. M. et al. (2011). Clouds at Arctic atmospheric observatories. Part I: Occurrence and macrophysical properties. Journal of Applied Meteorology and Climatology, 50, 626-644.

Solomon, S., Qin, D., Manning, M., Chen, Z., Marquis, M., Averyt, K. B., et al. (2007). Climate change 2007: The physical science basis. Contribution of Working Group I to the Fourth Assessment Report of the Intergovernmental Panel on Climate Change. Summary for Policymakers $18 \mathrm{pp}$.

Spangenberg, D. A., Chakrapani, V., Doelling, D. R., Minnis, P., \& Arduini, R. F. (2001). Development of an automated Arctic cloud mask using clear-sky satellite observations taken over the SHEBA and ARM-NSA sites. Proc. AMS 6th Conf. On Polar Meteorology and Oceanography, San Diego, CA, May 14-18.

Spangenberg, D. A., Doelling, D. R., Chakrapani, V., Minnis, P., \& Uttal, T. (2002). Nighttime cloud detection over the Arctic using AVHRR data. Proc. 12th ARM Science Team Meeting, St. Petersburg, FL, April 8-12.

Stephens, G. L., Vane, D. G., Boain, R. J., Mace, G. G., Sassen, K., Wang, Z. E., et al. (2002) The CloudSat mission and the A-train - A new dimension of space-based observations of clouds and precipitation. Bulletin of the American Meteorological Society, 83, 1771-1790.

Stephens, G. L., Vane, D. G., Tanelli, S., Im, E., Durden, S., Rokey, M., et al. (2008). CloudSat mission: Performance and early science after the first year of operation. Journal of Geophysical Research - Atmospheres, 113, D00A18.

Tjernström, M., Sedlar, J., \& Shupe, M. D. (2008). How well do regional climate models reproduce radiation and clouds in the Arctic? An evaluation of ARCMIP simulations. Journal of Applied Meteorology and Climatology, 47, 2405-2422.
Vaughan, M. A., Powell, K. A., Kuehn, R. E., Young S. A., Winker, D. M., Hostetler, C. A. et al. (2009). Fully automated detection of cloud and aerosol layers in the CALIPSO lidar measurements. Journal of Atmospheric and Oceanic Technology, 26, 2034-2050.

Vavrus, S. (2004). The impact of cloud feedbacks on Arctic climate under greenhouse forcing. Journal of Climate, 17, 603-615.

Vavrus, S., Holland, M. M., \& Bailey, D. A. (2011). Changes in Arctic clouds during intervals of rapid sea ice loss. Climate Dynamics, 36, 1475-1489.

Vavrus, S., \& Waliser, D. (2008). An improved parameterization for simulating Arctic cloud amount in the CCSM3 climate model. Journal of Climate, 21, 5673-5687.

Walsh, J. E., Kattsov, V. M., Chapman, W. L., Govorkova, V., \& Pavlova, T. (2002). Comparison of Arctic climate simulations by uncoupled and coupled global models. Journal of Climate, 15, 1429-1446.

Walsh, J. E., Vavrus, S. J., \& Chapman, W. L. (2005). Workshop on modeling of the Arctic atmosphere. Bulletin of the American Meteorological Society, 86, 845-852.

Wang, X. J., \& Key, J. R. (2003). Recent trends in Arctic surface, cloud, and radiation properties from space. Science, 299, 1725-1728.

Wang, X. J., \& Key, J. R. (2005). Arctic surface, cloud, and radiation properties based on the AVHRR Polar Pathfinder dataset. Part I: Spatial and temporal characteristics. Journal of Climate, 18, 2558-2574.

Welch, R. M., Kuo, K. S., \& Sengupta, S. K. (1990). Cloud and surface textural features in Polar Regions. IEEE Transactions on Geoscience and Remote Sensing, 28, 520-528.

Welch, R. M., Sengupta, S. K., \& Chen, D. W. (1988). Cloud field classification based upon high spatial-resolution textural features. 1. Gray level co-occurrence matrix approach. Journal of Geophysical Research - Atmospheres, 93, 12663-12681.

Welch, R. M., Sengupta, S. K., Goroch, A. K., Rabindra, P., Rangaraj, N., \& Navar, M. S. (1992). Polar cloud and surface classification using AVHRR imagery - An intercomparison of methods. Journal of Applied Meteorology, 31, 405-420.

Winker, D. M., Pelon, J., \& McCormick, M. P. (2003). The CALIPSO mission: Spaceborne lidar for observation of aerosols and clouds. Proceedings of SPIE, 4893, 1-11.

Wu, D. L., \& Lee, J. N. (2012). Arctic low cloud changes as observed by MISR and CALIOP: Implication for the enhanced autumnal warming and sea ice loss. Journal of Geophysical Research, 117, D07107. http://dx.doi.org/10.1029/2011JD017050.

Yamanouchi, T., Suzuki, K., \& Kawaguchi, S. (1987). Detection of clouds in Antarctica from infrared multispectral data of AVHRR. Journal of the Meteorological Society of Japan, 65, 949-962.

Yuan, J., Houze, R. A., Jr., \& Heymsfield, A. J. (2011). Vertical structures of anvil clouds of tropical mesoscale convective systems observed by CloudSat. Journal of Atmospheric Science, 68, 1653-1674. 